أثر ممارسات إدارة الموارد البشرية تجاه أدوار الأفراد على

تحقيق العدالة التنظيمية

في المؤسسات العامة - دراسة تطبيقية على وزارة الاتصالات

د/ منال محمد أحمد الوكيل

دكتوراة في فلسفة الإدارة العامة

\title{
الملخص
}

هدفت الدراسة الى بحث العلاقة بين ممارسات إدارة الموارد البشرية تجاه

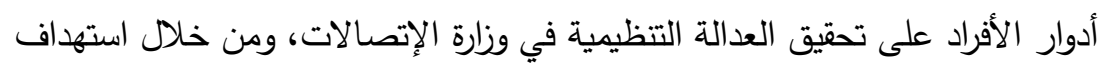

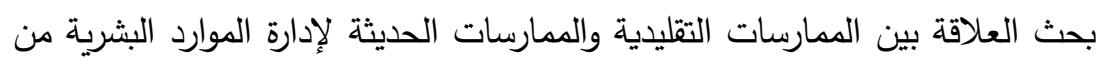

حيث علاقتها بالعدالة التظظيمية ومدى مساهمتها في تحقيقها بوزارة الإتصالات.

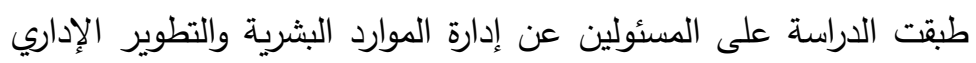

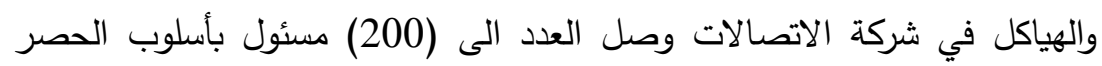

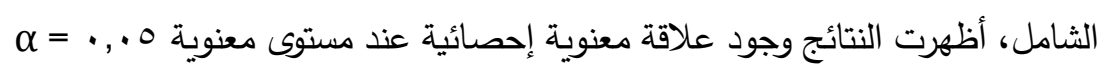

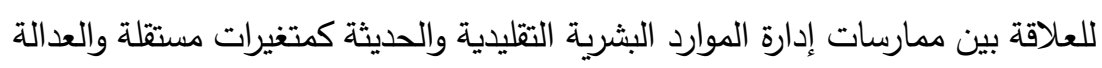
التنظيمية كمتغير تابع كما جاءت قيمة معامل الأنحدار معنوية عند مستوى معنوية

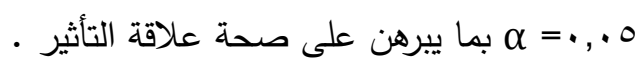
الدراسة أوصت بأن تعمل إدارة الموارد البشرية على الأخذ في الإعتبار تضمني ممارساتها الأنشطة التي تسهم في تعزيز العدالة التنظيمية بين العاملين في 
الوازرة كونها تسهم في تعزيز الرضا وزيادة الأنتاجية لدى العاملين وتحقيق فعالية الوزارة وكفاءة الوصول الى الأهداف. الكلمات الدالة: إدارة الموارد البشرية - الموارد البشرية - ممارسات إدارة الموارد

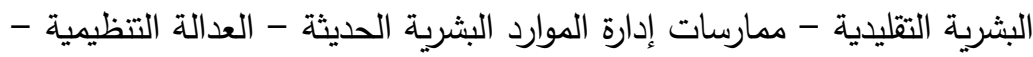
وزارة الإتصالات.

\section{التعربف الإجرائى}

ممارسات الموارد البثرية التقليدية هي تلك الأنشطة التي تقوم بها إدارة الموارد البشرية فيما يخص الدور التقليدي لها تجاه العاملين من حيث الإستقطاب والتعيين والترقية والتحفيز وتحديد الإحتياجات التدريبية وتقييم الأداء البشرى (Jesus, et.al, 2017). ممارسات الموارد البثرية الحديثة هي تلك الأنشطة التي تقوم بها إدارة الموارد البشرية تتعلق بالإتجاهات التهاته

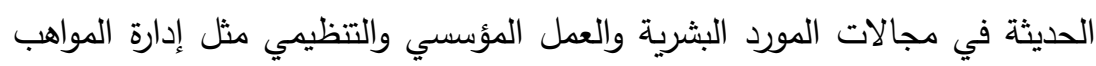

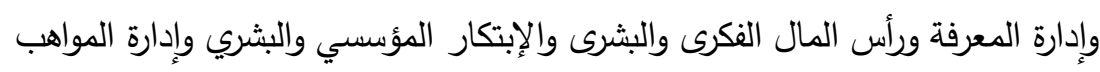
وبناء الأصول الفكرية (Virginia, et.al, 2018). العدالة التظظيمية الاصول هي الإجراءات العادلة التي يتم تطبيقها في المنظمة وتتيح للعاملين في جميع المستويات مسطرة موحدة للتعامل في كافة المواقف والحصول على الخدمات

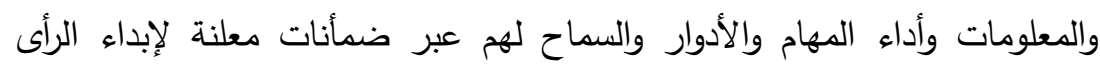

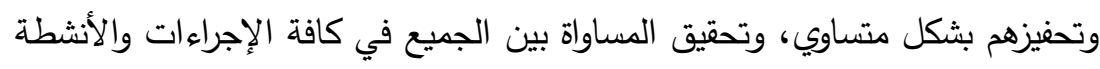
والحقوق والواجبات (Tayyaba ,et al.,2017). 
ممارسات إدارة الموارد البشرية التقليدية

ممارسات إدارة الموارد البشرية الحديثة

متغيرات تابعة

العدالة التظظيمية

العدالة الاجرائية

أثر ممارسات إدارة الموارد البشرية تجاه أدوار الأفراد

على تحقيق العدالة التظيمية في المؤسسات العامة

دراسة تطبيقية على وزارة الاتصالات

تأتى ممارسات إدارة الموارد البشرية ضمن التنظيم الإداري للمنظمات أحد أهم

العوامل المؤثرة في أداء الموظفين، حيث تتخذ تلك الممارسات الكثير من الأشكال والمظاهر التي تتعلق بالسياسات والإجراءات المرتبطة بالأداء البشرى والتحكم في نمط التراء ونوعية هذا الأداء، الأمر الذي أخذ اهتمامات الكثير من الأدبيات والدراسات الحديثة في مجال الموارد البشرية.

هناك تحولات مهمة في توجهات ممارسات إدارة الموارد البشرية توجبت أن تتخذ البذات تلك الممارسات ما يجعلها تتطابق والمتغيرات المعاصرة سواء كأنت في الأبعاد المادية

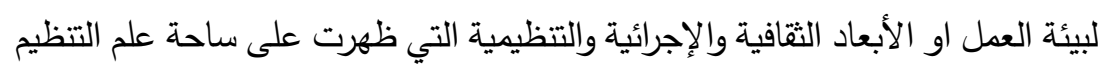

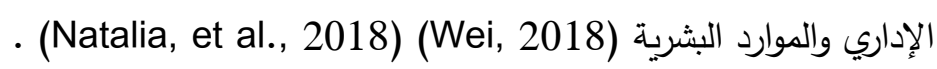
من بين تلك التوجهات رأس المال الفكرى والبشرى والمعرفة التنظيمية والإستراتيجية

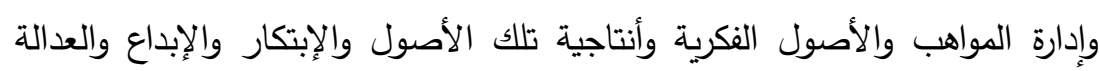


التنظيمية بكافة أشكالها، كلها أمور أصبحت تستوجب حدوث نقلة في ممارسات إدارة الموارد البشرية لكي تتتاسب معها.

وترى دراسات (Justin and Scott, (Tayyaba ,et al.,2017) (Benson and Martin, 2017) التي تتعلق بالأمور التنظيمية والبشرية في المؤسسة وأن هذا المفهوم يركز على عدة

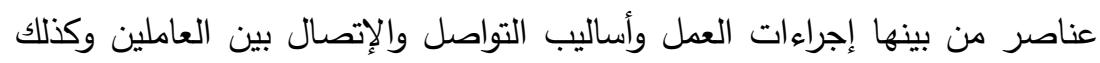
التحفيز والتعامل بين الزملاء، وتؤكد الدراسات على أن توجه الاهتمام بالعدالة وعناصرها المختلفة يعزز من قدرات المؤسسة التتظيمية والبشرية. لذلك تهتم الدراسة الحالية ببحث موضوع ممارسات إدارة الموارد البشرية والعدالة التنظيمية بوزارة الإتصالات من خلال دراسة تطبيقية على المسئولين بالوزارة ممن لهم علاقة بموضوع الدراسة. أهمية الدراسة

ترى دراسات عديدة سيتم ذكرها في مراجعة الأدبيات أن موضوع ممارسات

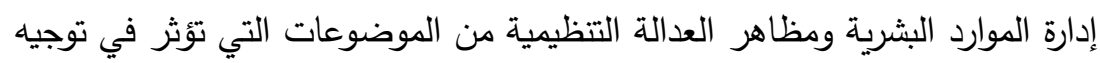
دفة الأداء المؤسسى والبشرى بالمؤسسة وإثاعة بيئة عمل داعمة لمواجهة تحديات

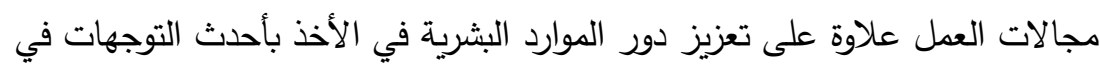
الأداء المؤسسى، لذلك تظهر أهمية الدراسة الحالية من منطلق أهمية ممارسات إدارة

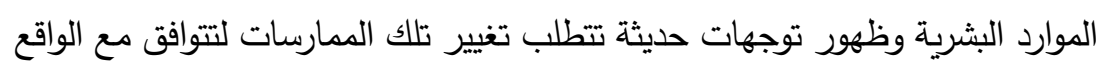

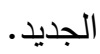
الأمر الآخر الذي يظهر أهمية الدراسة الحالية أهمية موضوع العدالة التظظيمية كأحد الموضوعات الحديثة في دراسات وأدبيات علم التنظيم المؤسسى واحتياج المكتبة العربية الى إثراء خلفية القارئ العربي عن هذا الموضوع، هناك أبعاد أخرى تظهر 
أهمية الدراسة الحالية تتعلق باستشراف واقع وزارة الإتصالات فيما يخص العدالة التتظيمية وأبعادها السائدة علاوة على واقع ممارسات إدارة الموارد البشرية وتقديم رؤية لإنية تطبيقية تساعد الوزارة في تفعيل دور ممارسات إدارة الموارد البشرية والعدالة التظيمية. الاراسات السابقة ممارسات إدارة الموارد البثرية تعتبر إدارة الموارد البشرية أحد الأركأن المهمة التى تعمل من خلالها المؤسسات في أمور وأنشطة تؤثر بصورة كبيرة على إدارتها لكافة العمليات المرتبطة الدئة بالموظفين في مستويات إدارية مختلفة (عبد الرحمن، 1 ( • ب).

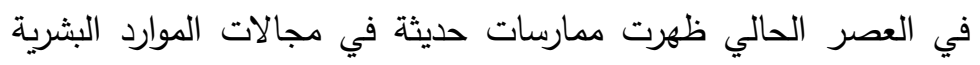
(Akram and Yusuf, 2016) (Judie, et.al, 2015) البشرى كأصل من الأصول المنتجة يشكل تحول مهم في ممارسات إدارة الموارد البشرية المعاصرة التى تعتبر الموظف مورد وأصل مهم مؤثر في أنتاجية المنظمة ومعرفتها الإستراتيجية وأصولها الفكرية. تتوه دراسات (Jesus, et.al, 2017) (Dolors, et.al, 2018) إلى أن وان هناك توجهات تؤيد الأنتقال من ممارسات ومهام ومسئوليات تقليدية تقوم بها الوحدات التتظيمية المسئولة عن كل ما يخص الموظفين إلى مهام وممارسات تعتمد في جوهرها

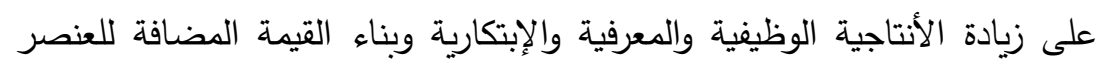
البشرى من خلال الأداء الوظيفى.

كما أن هناك جوأنب مهمة أوضحتها دراسات لوفئ (Virginia, et.al, 2018)

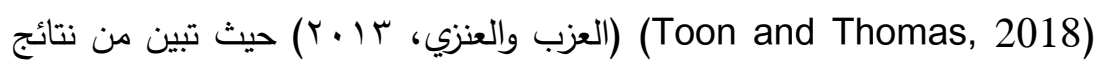
هذه الدراسات أن ممارسات إدارة الموارد البشرية أصحبت أداة مهمة في صورتها 
الحديثة التى تعمل وفق توجهات القدرة البشرية التى تعمل على بناء القدرة التتافسية للمنظمات بناءً على امتلاك الأصول الفكرية. دراسات كل من (Pelin, 2016) (Afagh, et.al, 2016) إهتمت ببحث مدى وجود علاقة بين ممارسات إدارة الموارد البشرية وتوجهات بناء رأس المال الفكرى

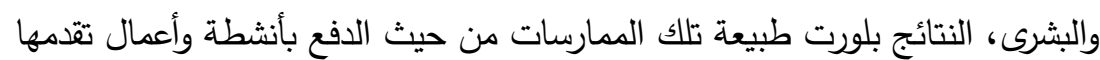

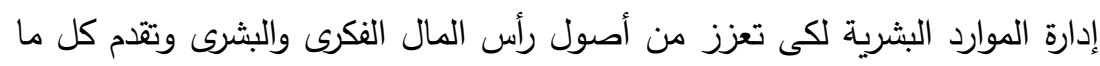
يؤدى الى زيادة قيمة تلك الأصول وزيادة العائد المتوقع منها. النتائج أوضحت كذلك مدى تأثير ممارسات إدارة الموارد البشرية في تعزيز العوامل التى تؤدى إلى مناخ مناسب لزيادة أصول رأس المال البشرى من حيث محفزات الابتكار والابداع والاقتراح الفردي وكذلك آليات التمكين الإدارى وأساليب التحفيز المادى والمعنوي. إن ممارسات إدارة الموارد البشرية تعد أساس الأداء الذى يمكن المنظمة من

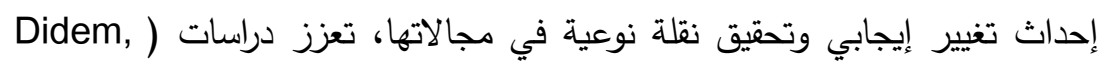
2016) (Zuzana and Jana, 2015) أدوار وممارسات إدارة الموارد البشرية دئية المتعلقة بالاختيار والاستقطاب والتعيين والتدريب أنها تؤثر في نقل المنظمة من الأداء التقليدي إلى الأداء القائم على بناء رأس المال الفكرى والبشرى والمعرفي.

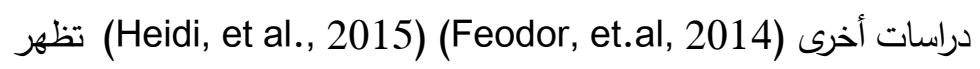
الباحثة أن هناك تحولات في توجهات ممارسات إدارة الموارد البشرية من منظور

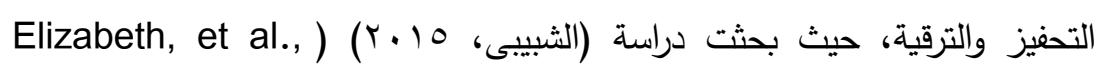
2017) مدى علاقة التحفيز والترقية ضمن عناصر ممارسات إدارة الموارد البشرية

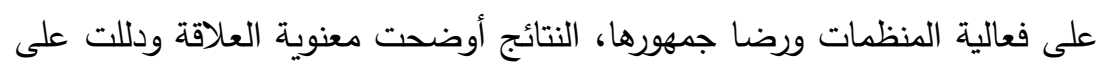


أن ممارسات إدارة الموارد البشرية تؤثر على الجوأنب اللامادية والمعنوية المرتبطة بالحالة النفية للموظفين وتزيد من دافعيتهم نحو الأنجاز .

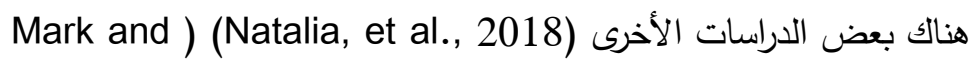

(Benon, 2018

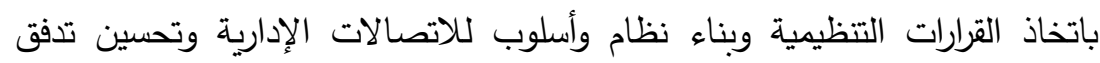
إجراءات العمل بالمنظمة، جاءت النتائج لتؤكد علاقة ممارسات إدارة الموارد البشرية

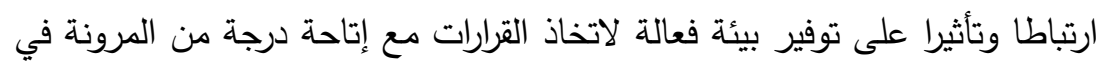

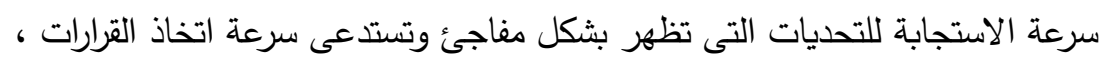

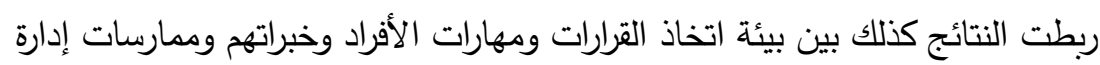
الموارد البشرية كوحدة تتظيمية.

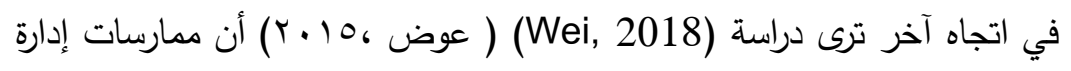
الموارد البشرية من المهم أن تقوم على سياسات واستراتيجية تراعى عدة أبعاد مرتبطة بكيأن وتتظيم المؤسسة ونوعية البناء الهيكلي الذي تقوم عليه، حيث اتضيح من التيات النتائج أن هناك تاثير وارتباط معنوي بين نمط الهيكل التنظيمى للمؤسسة وجدوى وفعالية استراتيجية الموارد البشرية والسياسات والإجراءات الخاصة بالعاملين، وأوضحت التئ النتائج

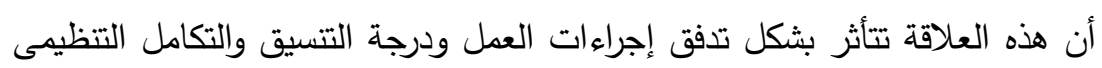
بين الوحدات والهيكل وممارسات إدارة الموارد البشرية. تتجه دراسات أخرى مثل دراسة (Sonal, et al., 2017) لبحث علاقة ممارسات إدارة الموارد البشرية بالجوأنب والمتغيرات التى تظهر على ساحة مجالات التهات العمل في

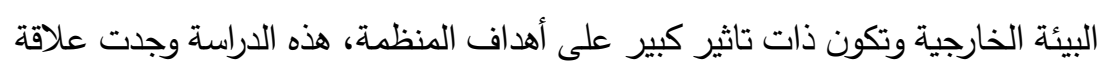

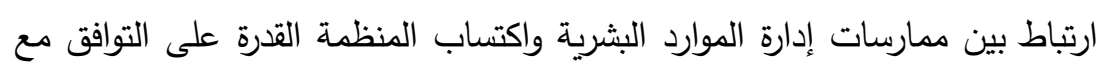

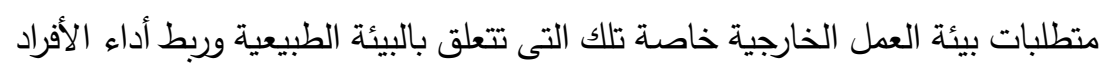


بأدوار الحفاظ على البيئة وعدم تلويثها وتحقيق الإستدامة الخضراء من ممارسات

$$
\text { الموارد البشرية (الزبيدى، } 1 \text { ( • ب). }
$$

Mohd, et al., ) هناك جوأنب تتعلق بأدوار وممارسات إدارة الموارد البثرية (بندية

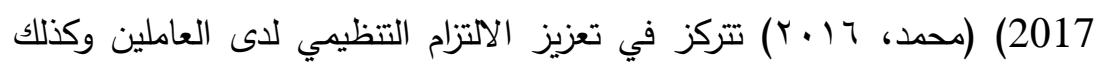

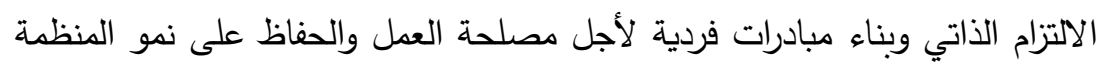

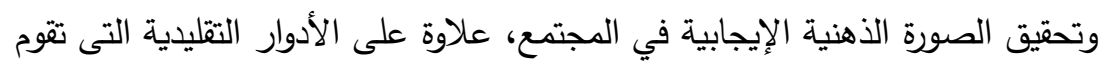
بها إدارة الموارد البشرية في كل ما يخص العاملين ويتيح لهم بيئة عمل مناسبة الإسية تساعدهم على العطاء والأنجاز وفق ما هو مستهدف ومخطط للجهود البشرية والتنظيمية. هناك تأثيرات تحدثها ممارسات إدارة الموارد البشرية على جوأنب مختلفة في المنظمة، دراسة (Elizabeth, et al., 2017) أوضحت أن من التأثيرات التى تترتب

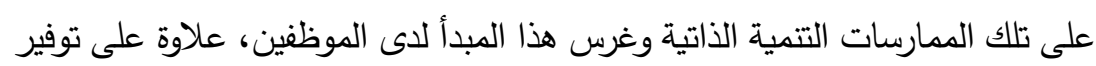

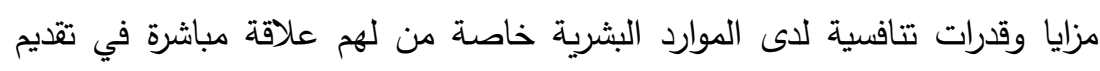
الخدمات والتعامل مع جمهور المستفيدين والأطراف المعنية بعمل المنظمة.

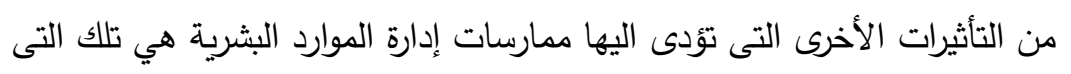

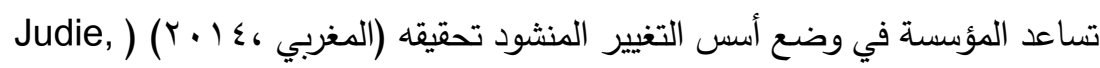

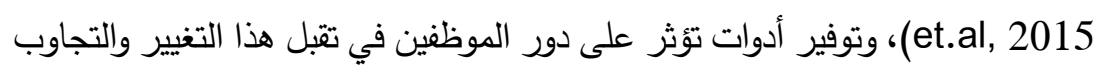
معه وتجنب حدوث ما يسمى بمقاومة التغيير التى تزيد من أعباء وتكاليف استقرار

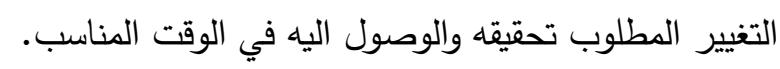

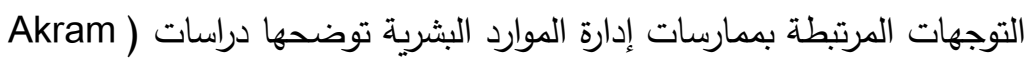
(Jesus, et.al, 2017) (and Yusuf, 2016 حيث تظهر النتائج تأثير الممارسات على السلامة المهنية وتوفير بيئة عمل مناسبة للحد من المخاطر الصحية 
والنفسية وتجنب ضغوط العمل، والتأثير كذلك على تقليل نسبة الأخطاء والمشاكل

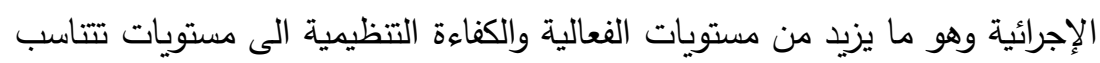
وأداء المؤسسة المنشود تحقيقه. من زاوي أخرى تؤثر ممارسات إدارة الموارد البشرية في مجال التقييم والقياس لأداء

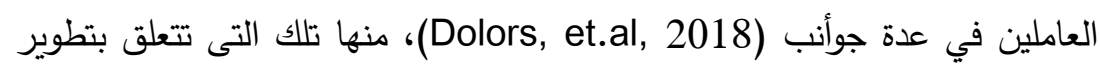

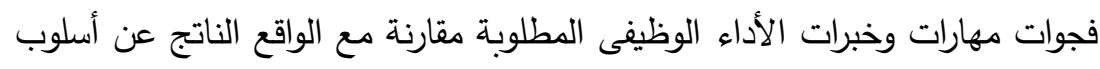

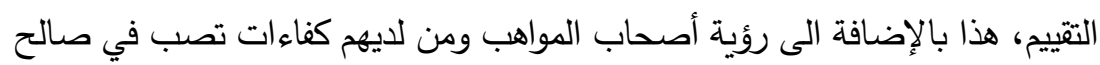

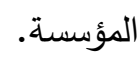

تأثيرات مهمة تؤديها ممارسات إدارة الموارد البشرية ذات العلاقة بالمدخلات والمخرجات التى تؤدى الى أداء المنظمة لأنشطتها وخدماتها ومنتجاتها، أكدت نتائج

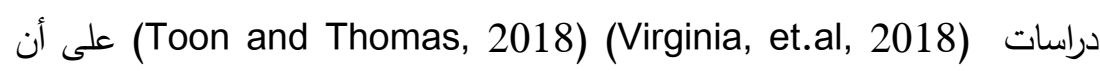
توجهات ممارسات إدارة الموارد البشرية ترتبط في مدخلات المنظمة التى يقوم الأفراد

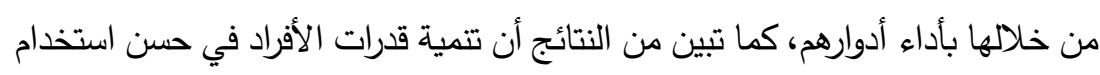
موارد المنظمة واتباع أفضل الطرق في توظيف الموارد المتاحة لتعظيم المخرجات

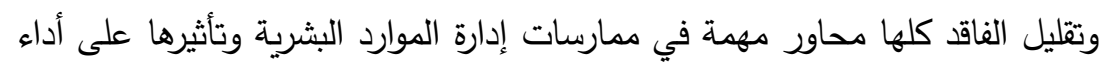
الموظفين.

تتجه بعض الدراسات المهتم في مجال ممارسات إدارة الموارد البشرية إلى تتاول

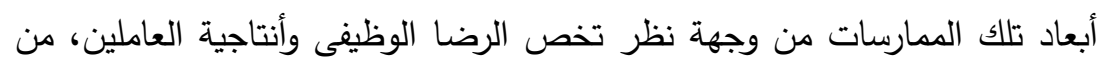
هذه الدراسات (Pfagh, et.al, 2016) (Pelin, 2016) حيث هدفت الى معرفة طبيعة العلاقة التى يتحقق من خلالها الرضا الوظيفى والأنتاجية البشرية المناسبة لطبيعة اهداف المنظمة والامكأنيات المتاحة التى يعمل الموظفين من خلالها للوصول

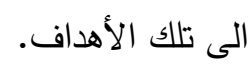


النتائج أظهرت أن هناك علاقة بين مستويات الرضا الوظيفى وبين أنتاجية الأداء

البشرى من زاوية الأهداف المؤسسية والأهداف الوظيفية، وأن تحدى ممارسات إدارة الموارد البشرية يكون في توفير سياسات تتناسب والربط بين متغيرات الرضا والأنتاجية وفى نفس الوقت الأهداف المؤسسية والبشرية. أفرزت كذلك دراسات في أدبيات الموارد البشرية تحولاً في توجهات هذه الممارسات (Woit, 2018) (Natalia, et al., 2018) أنطلق من عدة اعتبارات منها التكنولوجي والتتافسي والاستدامة واقتصاد المعرفة مما استوجب التعامل معها من خلال الموظفين وتقديم الأداء الوظيفى المناسب لها، الامر

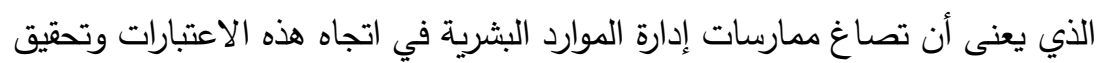
تأقلم أداء الموظفين مع استيعاب المتغيرات التكنولوجية وتوجهات المنافسة والاستدامة واقتصاد المعرفة بأداء وظيفي مناسب. 
بناءاً على ما سبق استعراضه من الاراسات السابقة في مجال ممارسات إدارة

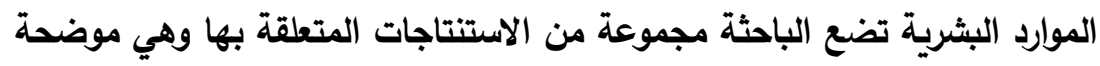

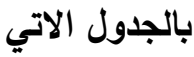

جدول رقم (1)

\begin{tabular}{|c|c|}
\hline استتتاجات الباحثة & الدراسات \\
\hline تغيير توجهات ممارسات إدارة الموارد البشرية لمواكبة العصر & $\begin{array}{r}\text { (Judie, et.al, 2015) (Akram and } \\
\text { Yusuf, 2016) }\end{array}$ \\
\hline والأصادة التركيز على الأصول البشرية وراس المال الفكرى والبشرى & $\begin{array}{r}\text { (Jesus, et.al, 2017) (Dolors, } \\
\text { et.al, 2018) }\end{array}$ \\
\hline 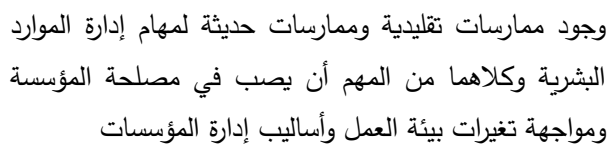 & $\begin{array}{r}\text { Zuzana and ) (Pelin, 2016) } \\
\text { Elizabeth, et al., ) (Jana, } 2015 \\
(2017\end{array}$ \\
\hline 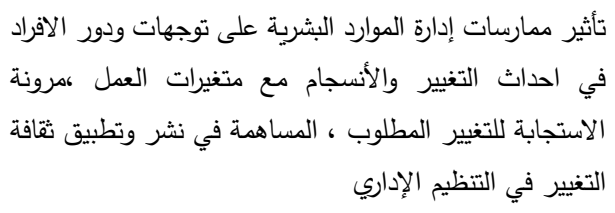 & $\begin{array}{r}\text { (Mark and Benon, 2018) } \\
\text { (Sonal, et al., 2017) }\end{array}$ \\
\hline 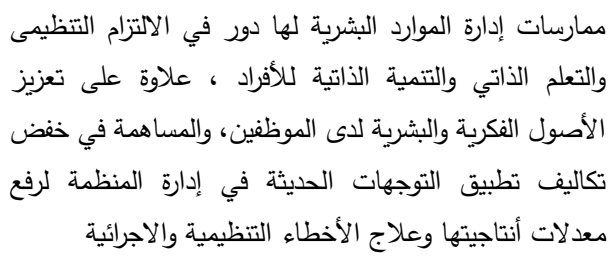 & $\begin{array}{r}\text { Natalia, et al., 2018) (Wei, } \\
\text { (2018) (Sonal, et al., } 2017\end{array}$ \\
\hline والتثير دور ممارسات الموارد البشرية على العلاقة بين المدخلات & $\begin{array}{r}\text { Toon and ) (Virginia, et.al, 2018) } \\
\text { (Thomas, 2018 }\end{array}$ \\
\hline
\end{tabular}




\section{العدالة التنظيمية}

هناك جوأنب تتعلق بموضوع العدالة التنظيمية بحثتها دراسة (عبد السميع، Y I ب)

(Tayyaba ,et al.,2017)

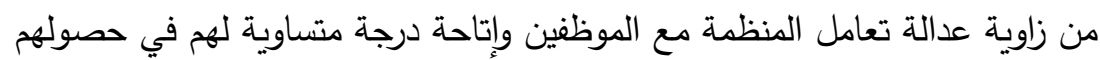
على الترقيات والتدريب وشفافية وعلأنية إجراءات التحفيز والترقية، وجدت النتائج علاقة بين العدالة التظيمية من حيث المساواة والثفافية وعلأنية الإجراءات والسلوكيات التى يظهرها الموظفون تجاه الاستعداد لتحمل أعباء العمل وتحقيق مصلحة المنظمة والمبادرة الذاتية الإيجابية في إطار ما يسمى بسلوكيات المواطنة التظظيمية.

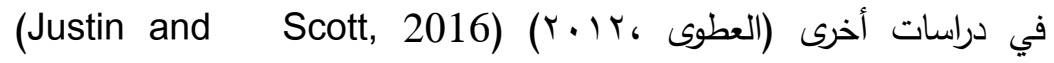
تتحدث عن معالجة قضايا وعلاقات العدالة (Benson and Martin, 2017) التتظيمية ببعض المتغيرات الأخرى، اتضح منها أن العدالة التظظيمية تركز على فض ون

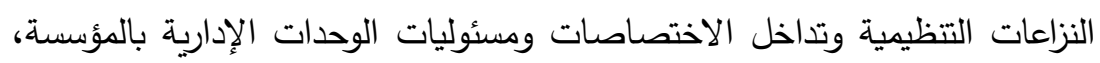
كما أن العدالة التظيمية تركز على وضع أسس مناسبة لإدارة العلاقات الإخلية بين

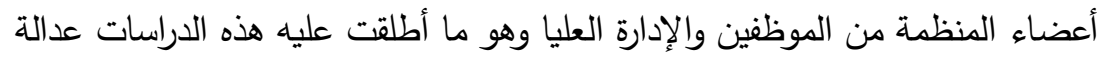
العلاقات وعدالة الاتصال والتواصل التظيمى والفردي. Debjani, et al., ) (Tan and Ab Aziz, 2016) تهتم دراسات أخرى 2016) بتقسيم موضوع العدالة التظيمية الى مجموعة من الأنماط والاشكال، تبين من النتائج ومن وجهة نظر العينة التى خضعت للدراسة أن هذه الأشكال من العدالة

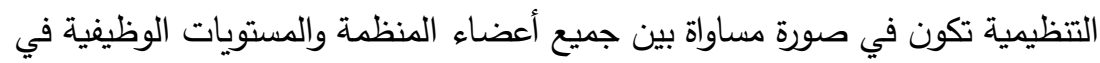
أمور الإجراءات والتوزيع والمخصصات الاجتماعية والمادية. 
وقد حددت هذه الدراسات ثلاثة أشكال من العدالة التنظيمية التى من الممكن أن تظهر في المؤسسات وهي العدالة الإجرائية والعدالة التوزيعية والعدالة العلاقية والاتصالات التنظيمية التى تقلل من الصراع التنظيمى.

من ناحية أخرى اعتبرت دراسة (Juliana, 2017) أن مفهوم العدالة التتظيمية أحد المفاهيم التى تساعد المؤسسة في توفير مناخ تتظيمي مناسب لأجراء التغيرات

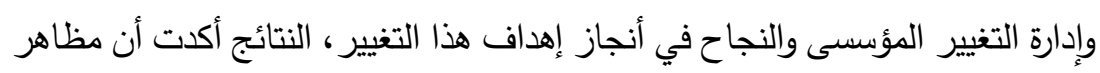

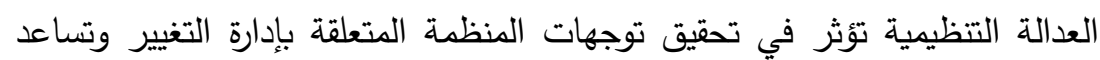

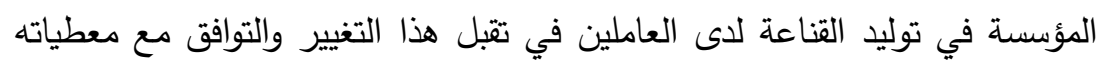
ومستجداته. في علاقة أخرى للعدالة التظظيمية والكفاءة التظظيمية جاءت نتائج دراسة لتوضح أن هناك دلالة (Ebru and Mine, 2016) (Silva , et al., 2016) معنوية إيجابية بين العدالة التتظيمية التى تتعلق بعدالة الإجراءات التتظيمية المطبقة

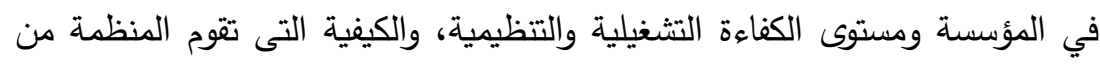

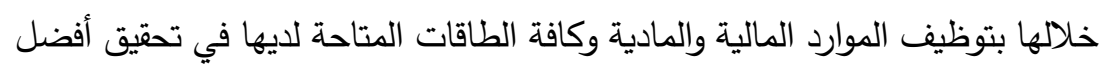
المخرجات وزيادة العوائد المتحققة من هذا الاستخدام. وقد أوضحت هذه الدراسات أن عدالة الإجراءات التتظيمية التى تمارسها المنظمة التهات تتصل بنوعية وطبيعة التكوين والكيأن التتظيمى الثائع لديها. هussell and Agustin, ) (Shannon, et al., 2015) هناك دراسات

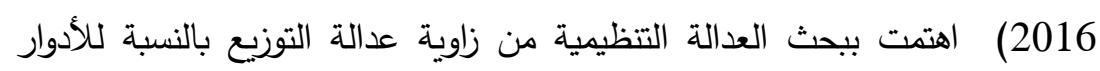
والمهام التى يتم إسنادها للموظفين وتأثير ذلك على بناء رأس المال الفكرى، اتضح

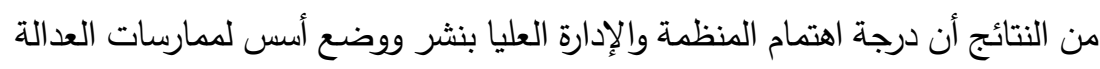
التوزيعية بين كافة الموظفين تؤثر في بناء رأس المال الفكرى من حيث أنئ أن هذه العدالة 
تؤدى إلى اتجاه العاملين نحو تبنى مبادرات في التتمية الذاتية بدوافع نابعة من داخلهم

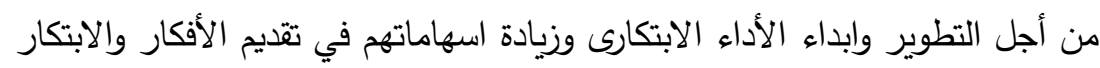
الذى يساعد في تطوير المؤسسة وبناء رأس المال الفكرى.

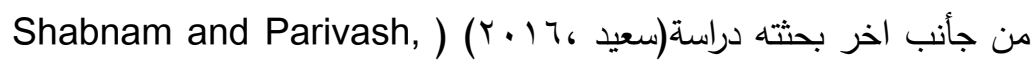
2012) للعلاقة بين استدامة الأداء المتميز وتوجهات الاستدامة وثقافة العدالة التنظيمية السائدة لدى المنظمات، طبقت الدراسة على عينة من الموظفين توصلت التصني

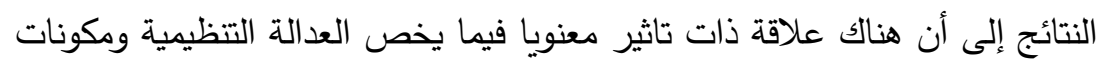

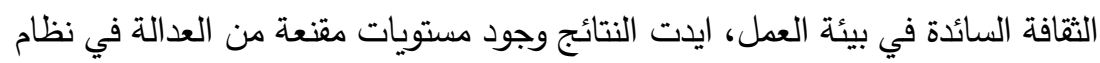
تقييم أداء الموظفين والمكونات المادية لبيئة العمل ومدى التسهيلات التى تقدمها المنظمة لموظفيها لتهيئة بيئة عمل مناسبة في تعزيز العدالة التتظيمية، وهنا الدراسة أكدت على أهمية عدالة بيئة العمل ومكوناتها.

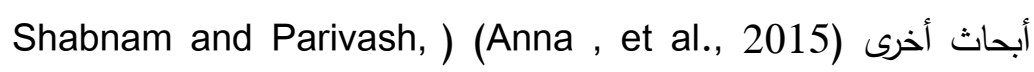

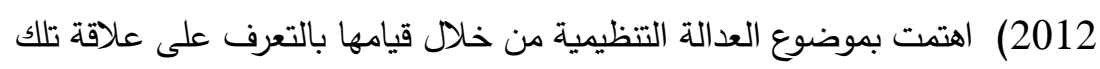
العدالة بالرضا والإدراك التنظيمي لها واستيعاب الموظفين والوحدات التتظيمية لمضمون العدالة التنظيمية الثائعة في المؤسسة، النتائج أظهرت أن الإدراك التظئيمي ولتئي للعدالة يتأثر بمستويات الرضا الوظيفى الثائعة في المؤسسة والإجراءات التى تتخذها المنظمة من أجل تحسين تلك المستويات. كذلك النتائج أظهرت تأثر العدالة التظيمية بنوعية الأساليب الإدارية الاتصالية

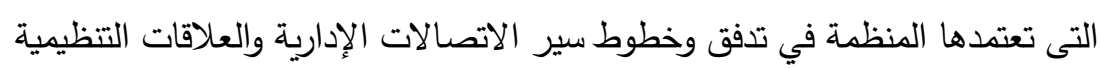
والبشرية. جأنب آخر في العدالة التظظيمية بحثت دراسة (Arzu, et al., 2014) عن

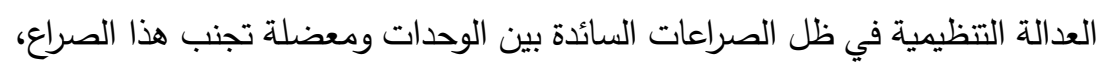


الدراسة ركزت على معرفة مدى وجود علاقة بين أبعاد ومعايير توجهات العدالة

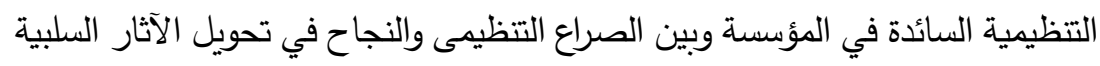
لهذا الصراع إلى الجأنب الإيجابى.

نتائج الدراسة جاءت لتؤكد العلاقة بين توجهات وأنماط العدالة التتظيمية السائدة في المنظمة وبين إدارة الصراع التتظيمي وتجاوز التحديات والنتائج السلبية المترتبة على هذا الصراع. تحتاج العدالة التنظيمية كلى عدة مقومات ينبغي أن تقوم المنظمة بتوفيرها، في

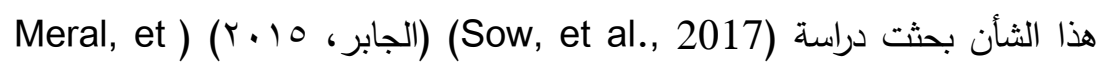
(al., 2015

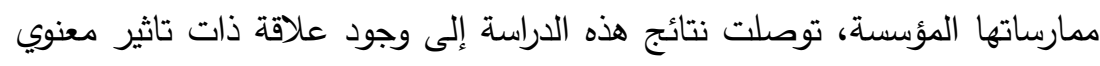
بين نمط وتوجه العدالة التتظيمية والثقة التتظيمية السائدة لاى الموظفين. حيث وضعت هذه الدراسات أبعاد مهمة تتعلق بتلك المقومات اللازمة للعدالة التنظيمية وهي توسيع دائرة التمكين الوظيفى، توفير أدوات لتقديم خدمات العدالة

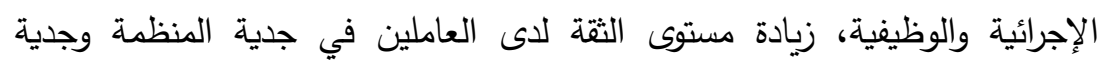

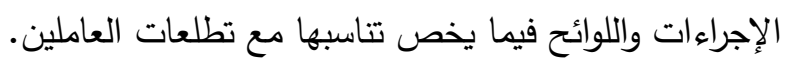
بناءاً على ما سبق استعراضه من الدراسات السابقة في مجال العدالة التنظيمية

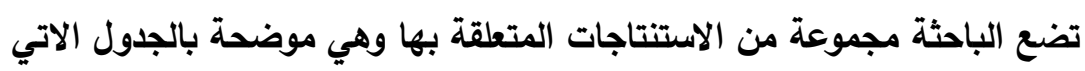


جدول رقم (2)

\begin{tabular}{|c|c|}
\hline 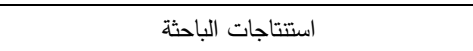 & 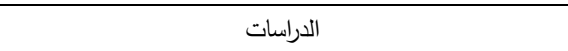 \\
\hline 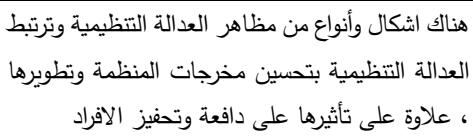 & $\begin{array}{r}\text { (Tan and Ab Aziz, 2016) (Debjani ,et al., 2016) } \\
\text { (Tayyaba ,et al.,2017) }\end{array}$ \\
\hline 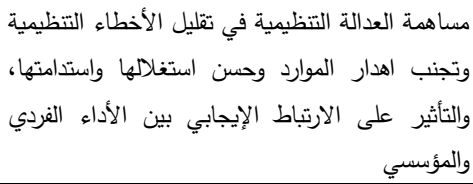 & (Silva, et al., 2016) (Ebru and Mine, 2016) \\
\hline 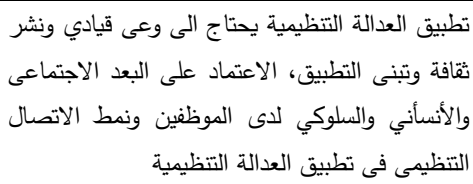 & $\begin{array}{r}\text { (Anna, et al., 2015) (Shabnam and Parivash, } \\
\text { 2012) }\end{array}$ \\
\hline 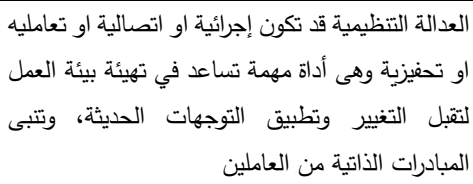 & $\begin{array}{r}\text { (Shannon, et al., 2015) (Juliana, 2017) } \\
\text { (Russell and Agustin, 2016) }\end{array}$ \\
\hline 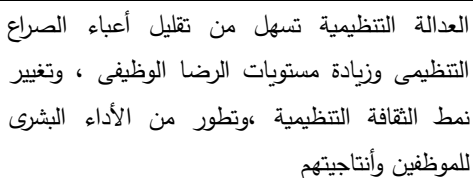 & $\begin{array}{r}\text { (Meral, et al., 2015) (Sow , et al., 2017) } \\
\text { (Arzu , et al., 2014) }\end{array}$ \\
\hline
\end{tabular}


في ضوء ما تقدم من الأدبيات والدراسات السابقة في ممارسات إدارة الموارد

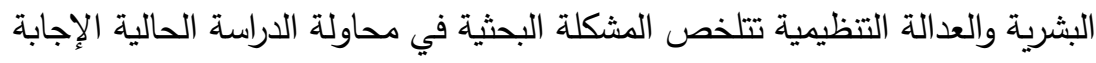

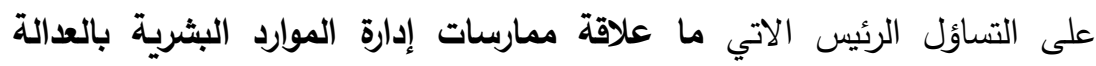
التنظيمية في وزارة الاتصالات؟ التباتي وينبثق منه الأسئلة الفرعية الاتية الاتصات

ما علاقة ممارسات إدارة الموارد البشرية التقليدية بالعدالة التظظيمية في وزارة الاتصالات؟

ما علاقة ممارسات إدارة الموارد البشرية الحديثة بالعدالة التتظيمية في وزارة الاتصالات؟

ما علاقة ممارسات إدارة الموارد البشرية التقليدية بالعدالة الإجرائية في وزارة الاتصالات؟

ما علاقة ممارسات إدارة الموارد البشرية الحديثة بالعدالة الإجرائية في وزارة

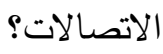


تسعى الدراسة الحالية الى تحقيق مجموعة من الأهداف التي تتسجم مع طبيعة المشكلة البحثية والافتراضات التي تقوم عليها، وهي مبينة كما يلي: 1. بحث مدى وجود علاقة بين ممارسات إدارة لموارد البشرية التقليدية والعدالة التظيمية بوزارة الاتصالات.

r. استكثاف مدى علاقة ممارسات إدارة لموارد البشرية الحديثة والعدالة

$$
\text { التظيمية بوزارة الاتصالات. }
$$

r. تحديد طبيعة علاقة ممارسات إدارة الموارد البشرية التقليدية والحديثة بالعدالة

$$
\text { الإجرائية في وزارة الاتصالات. }
$$

ء. اقتراح مجموعة من التوصيات المناسبة التي من المككن أن تسهم في تعزيز

دور ممارسات إدارة الموارد البشرية تجاه الافراد للعدالة التتظيمية والإجرائية

$$
\text { الفروض البحثية وزارة الإتصالات. }
$$

تقوم الدراسة الحالية على اختبار مدى صحة الفروض البحثية الآتية

H01 الفرض الفرعي الأول: لا توجد علاقة ذات دلالة إحصائية عند

مستوى معنوية ه., ه م بين ممارسات إدارة الموارد البشرية والعدالة

$$
\text { التظيمية في وزارة الاتصالات. }
$$

H02 الفرض الفرعي الثاني: لا توجد علاقة ذات دلالة إحصائية عند مستوى

معنوية ه., م= بين ممارسات إدارة الموارد البشرية التقليدية والعدالة

$$
\text { التظيمية في وزارة الاتصالات. }
$$


H03 الفرض الفرعي الثالث: لا توجد علاقة ذات دلالة إحصائية عند مستوى

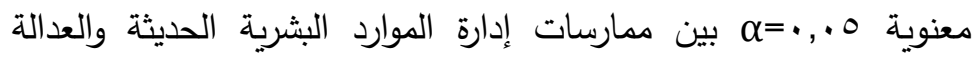
التظيمية في وزارة الاتصالات.

H04 الفرض الفرعي الرابع: لا توجد علاقة ذات دلالة إحصائية عند مستوى ولاتص معنوية ه., م= م بين ممارسات إدارة الموارد البشرية التقليدية والعدالة الاجرائية في وزارة الاتصالات.

H05 الفرض الفرعي الخامس: لا توجد علاقة ذات دلالة إحصائية عند الفات مستوى معنوية ه . ., •. 0 بين ممارسات إدارة الموارد البشرية الحديثة والعدالة الاجرائية في وزارة الاتصالات. كما توضح الباحثة علاقات متغيرات الفروض البحثية في الثكل التالي

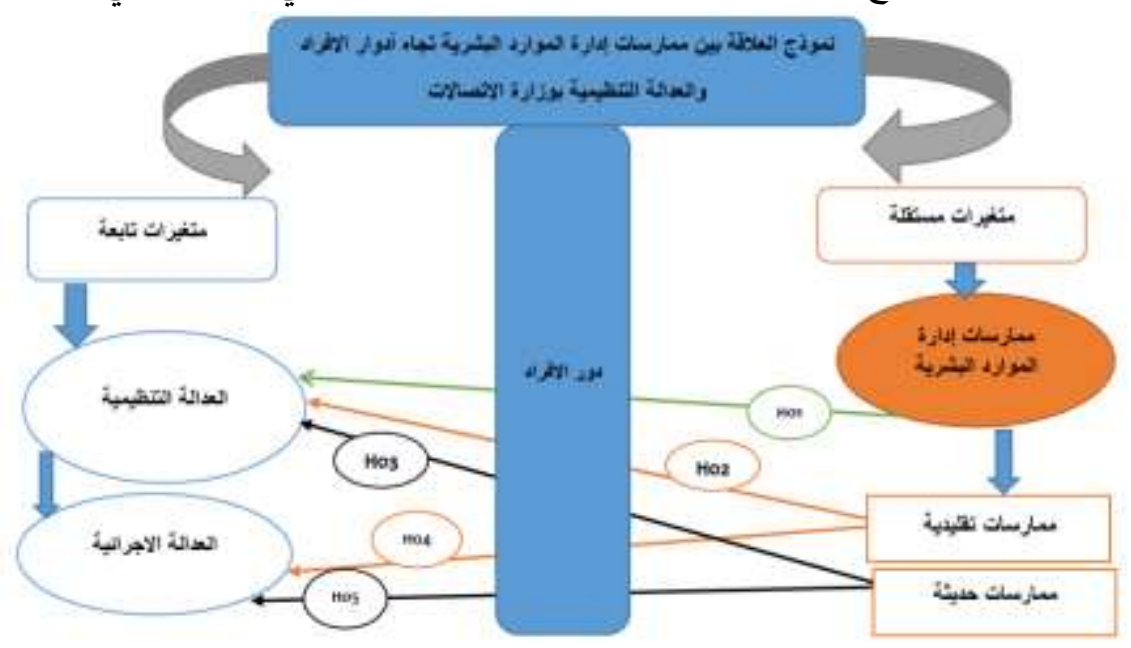

شكل (1) نموذج علاقات متغيرات الدراسة بين ممارسات إدارة الموارد البشرية تجاه أدوار الأفراد والعدالة التتظيمية بوزارة الاتصالات. الثكل من إعداد الباحثة 


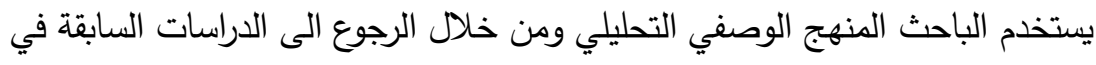

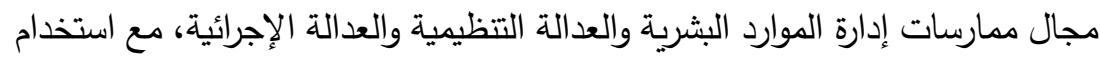

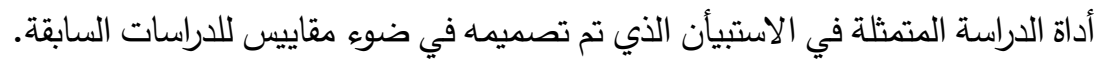
مجتمع وعينة الداسة الداسة يتمثل مجتمع الدراسة في شركات الاتصالات. عينة الاراسة

استخدمت الباحثة أسلوب الحصر الثامل للمسئولين عن إدارة الموارد البشرية والتطوير الإداري والهياكل في شركة الاتصالات وصل العلابلة العدد إلى (200) مسئول.

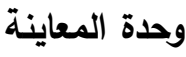
والمسئولين في شركة الاتصالات عن إدارة الموارد البشرية والتطوير الإداري والهياكل. تصميم أداة الاراسة

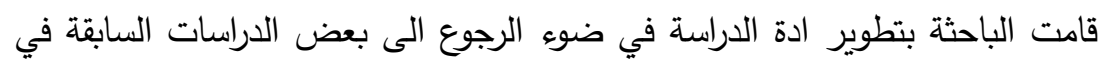

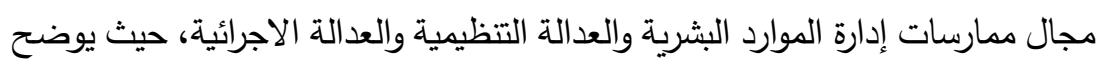
ذلك من خلال الجدول التالي التي 
جدول (3) محاور وفقرات أداة الداسة

\begin{tabular}{|c|c|c|}
\hline الدراسات السابقة المرجعية الدية & القياس & 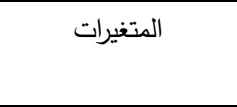 \\
\hline $\begin{array}{r}\text { (Judie, et.al, 2015) (Akram and Yusuf, 2016) } \\
\text { (Jesus, et.al, 2017) (Dolors, et.al, 2018) }\end{array}$ & Tr & البشرية إلمات إدارة الموارد \\
\hline $\begin{array}{r}\text { Pelin, 2016) (Zuzana and Jana, 2015) (Elizabeth, ) } \\
\text { (et al., } 2017\end{array}$ & 10 & البشرية التقليدية إدارة الموارد \\
\hline (Mark and Benon, 2018) (Sonal, et al., 2017) & IV & البشرية الحديثة إدارة الموارد \\
\hline (Tan and Ab Aziz, 2016) (Debjani ,et al., 2016) & $r \varepsilon$ & 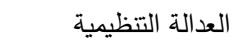 \\
\hline $\begin{array}{r}\text { (Tayyaba ,et al.,2017) } \\
\text { (Silva , et al., 2016) (Ebru and Mine, 2016) } \\
\text { (Anna , et al., 2015) (Shabnam and Parivash, 2012) }\end{array}$ & 1. & 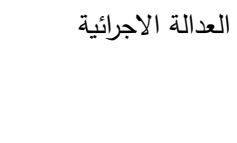 \\
\hline
\end{tabular}




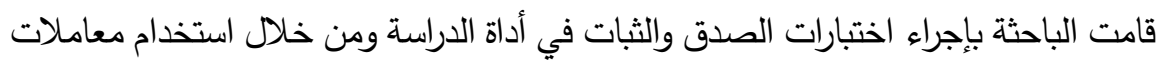
ألفا كرونباخ ومعامل الإرتباط الذي يثير الى الصدق والثبات وهو موضتح في الجداول الآتية

جدول رقم (4) معاملي الثبات والصدق لمحاور أداة الدراسة

\begin{tabular}{|c|c|c|}
\hline معامل الصدق & 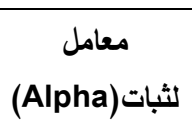 & محاور أداة الدراسة \\
\hline 0.85517 & 0.7569 & ممارسات إدارة الموارد البشرية \\
\hline 0.9145 & 0.8363 & ممارسات إدارة الموارد البشرية التقليدية \\
\hline 0.8765 & 0.7682 & ممارسات إدارة الموارد البشرية الحديثة \\
\hline 0.8688 & 0.7548 & العدالة التنظيمية \\
\hline 0.9201 & 0.8465 & العدالة الاجرائية \\
\hline
\end{tabular}

أسلوب سحب العينة وتطبيق أداة الدراسة

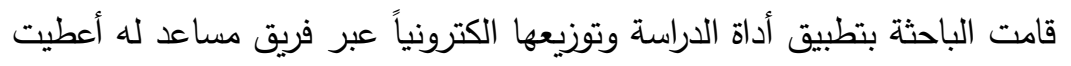

لهم التعليمات حول الدراسة وطبيعتها، كما قامت الباحثة بتحديد وتوفير أدوات اتصال

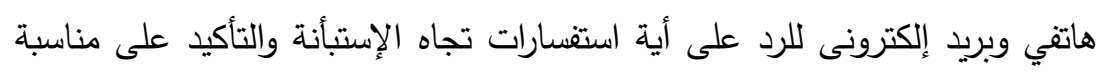

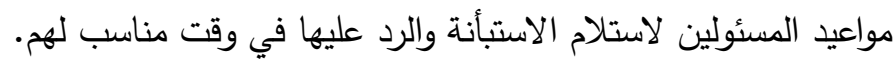


تثير الباحثة الى اختبار فروض الدراسة على الدى النحو الموضه الموضح بعد: اختبار وتحليل الفرض البحثي الأول: ينص هذا الفرضي على "H01 الفرض الأول: لا توجد علاقة ذات دلالة إحصائية عند مستوى معنوية ه ., م= بين ممارسات إدارة الموارد البشرية والعدالة التتظيمية

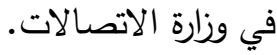

$$
\text { توضح جداول (5) (6) نتائج اختبار الفرض الأول وهي كما يلي }
$$

جدول رقم (5)

معامل ارتباط بيرسون لقياس العلاقة بين ممارسات إدارة الموارد البشرية والعدالة

\begin{tabular}{|c|c|c|c|}
\hline \multicolumn{4}{|c|}{ التتظيمية في وزارة الاتصالات } \\
\hline (النتيجة & المعنوية & 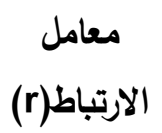 & العلاقة \\
\hline 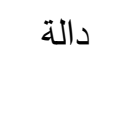 & $* * 0.009$ & $* * 0.878$ & والعدالة التنظيمية في وزارسات إدارة الموارد البشرية \\
\hline
\end{tabular}




\section{جدول رقم (6)}

نموذج الأنحدار الخطي البسيط لتحديد معنوية تأثير ممارسات إدارة الموارد البشرية والعدالة التنظيمية في وزارة الاتصالات

\begin{tabular}{|c|c|c|c|c|c|c|}
\hline \multirow[t]{2}{*}{$\begin{array}{c}\text { معامل التحديد } \\
\text { R }^{2}\end{array}$} & \multicolumn{2}{|c|}{$\begin{array}{l}\text { قيمة "ف" } \\
\text { F. test }\end{array}$} & \multicolumn{2}{|c|}{$\begin{array}{l}\text { قيمة "ت" test } \\
\text { t. test }\end{array}$} & \multirow{2}{*}{$\begin{array}{c}\text { المقدرة } \\
\beta_{i}\end{array}$} & \multirow[t]{2}{*}{ المتغير المستقل } \\
\hline & مستوى المعنوية & القيمة & المعنوية & القيمة & & \\
\hline \multirow[t]{2}{*}{$77.1 \%$} & $* * 0.009$ & 441.120 & ** *0.009 & 3.105 & 0.399 & ممارسات إدارة الموارد البشرية \\
\hline & & & $* * 0.009$ & 21.515 & 0.891 & \\
\hline
\end{tabular}

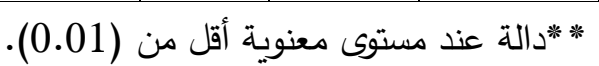

بالنظر الى نتائج جدولي (5) (6) لاختبار الفرض الأول يتضح مند أن هناك علاقة

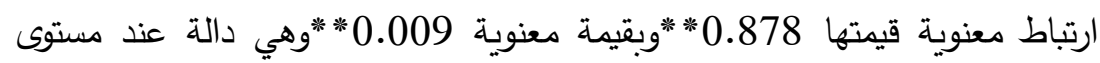
معنوية أقل من (0.01) الأمر الذي يعنى صحة العلاقة ممارسات إدارة الموارد البشرية

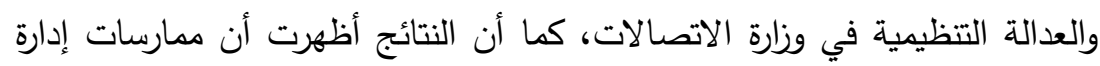

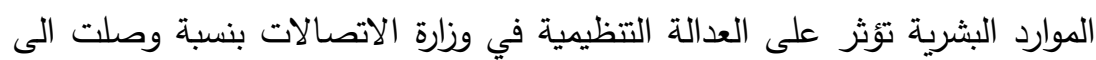

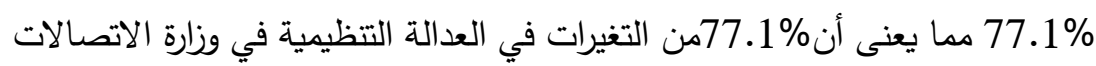
ترجع الى ممارسات إدارة الموارد البشرية. بناءاً على ما سبق في دراسة الفرض الأول " لا توجد علاقة ذات دلالة إحصائية عند مستوى معنوية

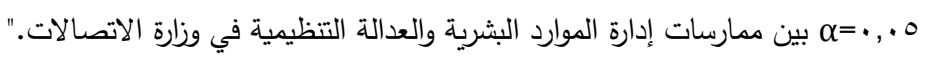
يتضح وجود علاقة بين ممارسات إدارة الموارد البشرية والعدالة التظيمية في وزارة الاتصالات وتوافق نتائج بعض الدراسات مع عناصر متغيرات الفرضية والعلاقة بينهم لبنه 


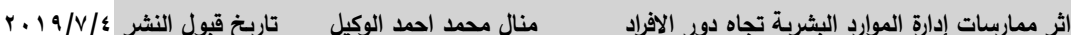

$$
\text { اختبار وتحليل الفرض البحثي الثأني: }
$$

ينص هذه الفرض على "H02 الفرض الثاني: لا توجد علاقة ذات دلالة إحصائية عند

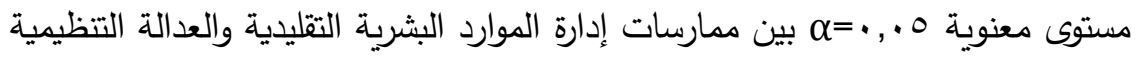
في وزارة الاتصالات. توضح جداول (7) (8) نتائج اختبار الفرض الثأني وهي كما يلي

جدول رقم (7)

معامل ارتباط بيرسون لقياس العلاقة بين ممارسات إدارة الموارد البشرية التقليدية والعدالة التظيمية في وزارة الاتصالات

\begin{tabular}{|c|c|c|c|}
\hline النتيجة (الالالة) & مستوى المعنويِة & الارتباط(r) & العلاقة \\
\hline دالة & $* * 0.006$ & $* * 0.825$ & بين ممارسات إدارة الموارد البشرية \\
\hline
\end{tabular}

جدول رقم (8)

نموذج الأنحدار الخطي البسيط لتحديد معنوية تأثير ممارسات إدارة الموارد البشرية التقليدية والعدالة التنظيمية في وزارة الاتصالات

\begin{tabular}{|c|c|c|c|c|c|c|}
\hline \multirow{2}{*}{$\begin{array}{c}\text { التحديد } \\
\text { R }^{2}\end{array}$} & \multicolumn{2}{|c|}{ قيمة "ف" } & \multicolumn{2}{|c|}{$\begin{array}{l}\text { قيمة "ت" } \\
\text { t. test }\end{array}$} & \multirow{2}{*}{$\begin{array}{l}\text { المعلمات } \\
\beta_{i}\end{array}$} & \multirow[t]{2}{*}{ المتغير المستقل } \\
\hline & المعنوية & القيمة & مستوى & القيمة & & \\
\hline $68.1 \%$ & $* * 0.006$ & 191.220 & **00.006 & 5.366 & 0.465 & ممارسات إدارة الموارد \\
\hline & & & ***0.006 & 13.655 & 0.781 & \\
\hline
\end{tabular}




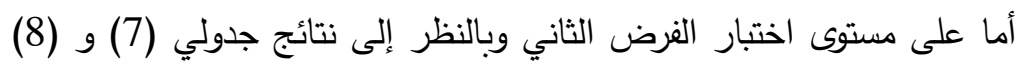

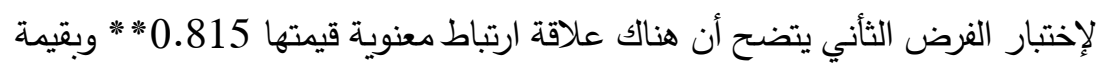

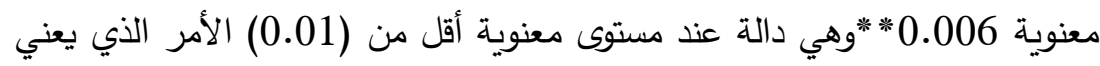
صحة العلاقة بين ممارسات إدارة الموارد البشرية التقليدية والعدالة التنظيمية في وزارة التارية الاتصالات، كما أن النتائج أظهرت أن ممارسات إدارة الموارد البشرية التقليدية تؤثر

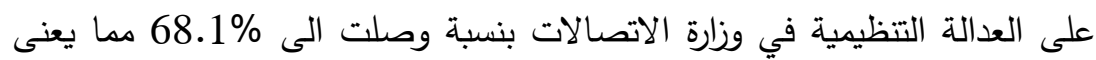

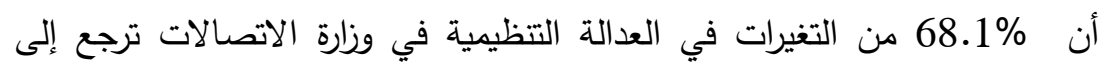
ممارسات إدارة الموارد البشرية التقليدية. إختبار وتحليل الفرض البحثي الثالث: ينص هذا الفرض على "H03 الفرض الثالث: لا توجد علاقة ذات دلاللة إحصائية عند

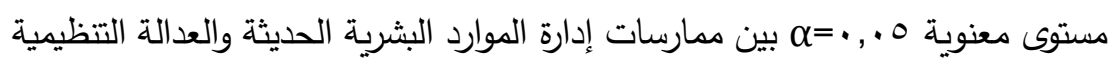

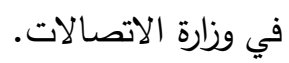
توضح جداول (9) (10) نتائج اختبار الفرض الثالث وهي كما يلي

جدول رقم (9)

معامل ارتباط بيرسون لقياس العلاقة بين ممارسات إدارة الموارد البشرية الحديثة

\begin{tabular}{|c|c|c|c|}
\hline (النتيجة & 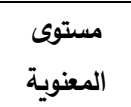 & $\begin{array}{c}\text { الارتباط(r) معامل } \\
\text { (r) }\end{array}$ & العلاقة \\
\hline دالة & ***0.008 & * * 0.891 & ممارسات إدارة الموارد البشرية الحديثة والعدالة \\
\hline
\end{tabular}

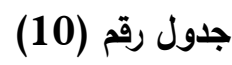

AYr

المجلة العلمية للاقتصاد والتجارة 
نموذج الأنحدار الخطي البسيط لتحديد معنوية تأثير ممارسات إدارة الموارد البشرية الحديثة والعدالة التتظيمية في وزارة الاتصالات

\begin{tabular}{|c|c|c|c|c|c|c|}
\hline \multirow{2}{*}{$\begin{array}{c}\text { معامل } \\
\text { التصديد } \\
\mathbf{R}^{2}\end{array}$} & \multicolumn{2}{|c|}{$\begin{array}{l}\text { قيمة "ف" test } \\
\text { F. test }\end{array}$} & \multicolumn{2}{|c|}{$\begin{array}{l}\text { قيمة "ت" test } \\
\text { t. test }\end{array}$} & \multirow{2}{*}{$\begin{array}{c}\text { المقدرة } \\
\beta_{i}\end{array}$} & \multirow[t]{2}{*}{ المتغير المستقل } \\
\hline & المعنوية & القيمة & المعنوية & القيمة & & \\
\hline \multirow[t]{2}{*}{$79.4 \%$} & ***0.008 & 401.955 & $0.008^{* * *}$ & 2.499 & 0.435 & ممارسات إدارة الموارد \\
\hline & & & $0.008^{* * *}$ & 20.420 & 0.7775 & \\
\hline
\end{tabular}

.

ومن نتائج جدولي (9) (10) لاختبار الفرض الثالث يتضح من أن هناك علاقة ارتباط

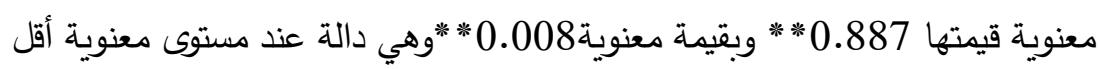
من (0.01) الأمر الذي يعنى صحة العلاقة بين ممارسات إدارة الموارد البشرية

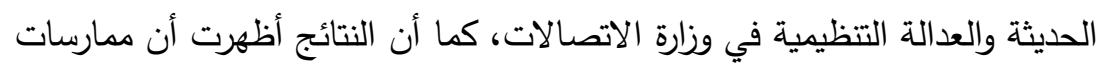

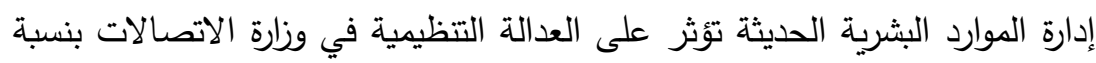
وصلت الى 79.4 79ما يعنى أن 79.4من التغيرات في العدالة التظظيمية في وزارة الاتصالات ترجع إلى ممارسات إدارة الموارد البشرية الحديثة.

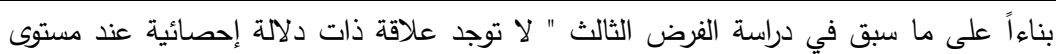
معنوية ه . . .= $\alpha$ بين ممارسات إدارة الموارد البشرية الحديثة والعدالة التظظيمية في وزارة الاتصالات.

يتضح وجود علاقة بين بين ممارسات إدارة الموارد البشرية الحديثة والعدالة التنظيمية في وزارة الاتصالات ناتجة عن توافق نتائج بعض الدراسات مع عناصر متغيرات الفرضية والعلاقة بينهر 
ينص هذا الفرض على "H04 الفرض الرابع: لا توجد علاقة ذات دلالة إحصائية عند مستوى معنوية ه., م= مبين ممارسات إدارة الموارد البشرية التقليدية والعدالة الإجرائية في وزارة

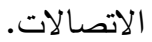
توضح جداول (11) (12) نتائج اختبار الفرضية الرابعة وهي كما يلى

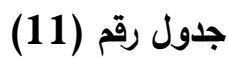

معامل ارتباط بيرسون لقياس العلاقة بين ممارسات إدارة الموارد البشرية التقليدية والعدالة الإجرائية في وزارة الاتصالات

\begin{tabular}{|c|c|c|c|}
\hline النتيجة (الدلالة) & المعنوية & $\begin{array}{c}\text { معامل الارتباط(r) } \\
\text { (r) }\end{array}$ & العلاقة \\
\hline دالة & $* * 0.006$ & $* * 0.791$ & 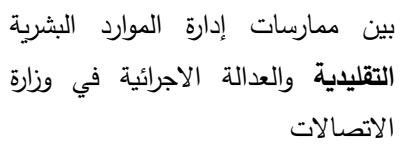 \\
\hline
\end{tabular}

(0.01).

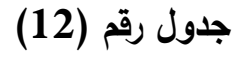

نموذج الأنحدار الخطي البسيط لتحديد معنوية تأثير بين ممارسات إدارة الموارد البشرية التقليدية والعدالة الاجرائية في وزارة الاتصالات

\begin{tabular}{|c|c|c|c|c|c|c|}
\hline \multirow{2}{*}{$\begin{array}{c}\text { التحدامل } \\
\text { Re } \\
\text { R }^{2}\end{array}$} & \multicolumn{2}{|c|}{ 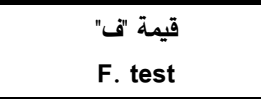 } & \multicolumn{2}{|c|}{$\begin{array}{l}\text { قيمة "ت" test } \\
\text { t. test }\end{array}$} & \multirow{2}{*}{$\begin{array}{c}\text { المقلمات } \\
\beta_{i}\end{array}$} & \multirow[t]{2}{*}{ المستقل } \\
\hline & المعنوية & القيمة & المعنوية & القيمة & & \\
\hline \multirow[t]{2}{*}{$62.6 \%$} & $* * 0.006$ & 405.912 & $0.006^{* * *}$ & 2.942 & 0.412 & الموارد البشرية إدارة \\
\hline & & & $0.006^{* * *}$ & 20.412 & 0.813 & \\
\hline
\end{tabular}

"0.01). (0.01). 
تبين من نتائج جدول (11) و(12) المتعلقة باختبار الفرض الرابع أن هناك علاقة

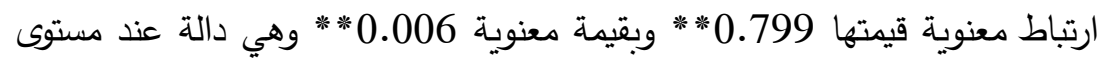
معنوية أقل من (0.01) الأمر الذي يعنى صحة العلاقة بين ممارسات إدارة الموارد

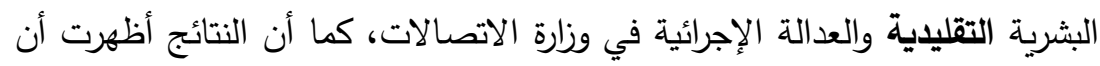

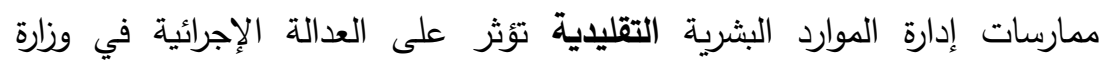
الاتصالات بنسبة وصلت إلى 62.62 مما يعنى أن 62.6 من من التغيرات في العدالة الإجرائية في وزارة الإتصالات ترجع إلى ممارسات إدارة الموارد البشرية

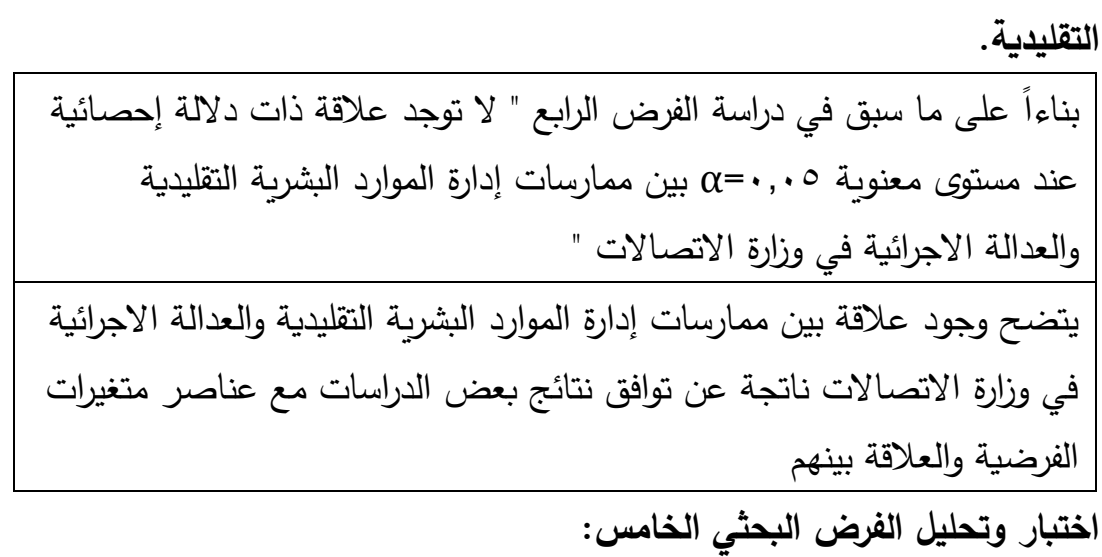
ينص هذ الفرض على "H05 الفرض الخامس: لا توجد علاقة ذات دلالة إحصائية

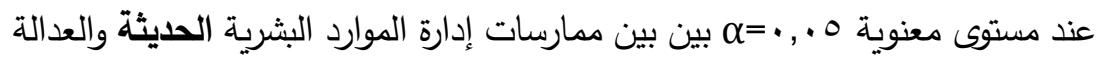
الاجرائية في وزارة الاتصالات. توضح جداول (13) (14) نتائج اختبار الفرض الخامس وهي كما يلي 


\section{جدول رقم (13)}

معامل ارتباط بيرسون لقياس العلاقة بين ممارسات إدارة الموارد البشرية الحديثة

\begin{tabular}{|c|c|c|c|}
\hline النتيجة (الدلالة) & مستوى المعنوية & $\begin{array}{c}\text { الارتباط(r) } \\
\text { (r) }\end{array}$ & العلاقة \\
\hline دالة & $* * 0.002$ & $* * 0.826$ & العديثة والعدالة الاجرائية في البراتية \\
\hline
\end{tabular}

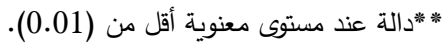

\section{جدول رقم (14)}

نموذج الأنحدار الخطي البسيط لتحديد معنوية تأثير ممارسات إدارة الموارد البشرية العديثة والعدالة الاجرائية في وزارة الاتصالات

\begin{tabular}{|c|c|c|c|c|c|c|}
\hline \multirow{2}{*}{$\begin{array}{c}\text { معامل } \\
\text { التحديد } \\
\mathbf{R}^{2}\end{array}$} & \multicolumn{2}{|c|}{ قيمة "ف" } & \multicolumn{2}{|c|}{ قيمة "ت" } & \multirow{2}{*}{$\begin{array}{c}\text { المقدمات } \\
\beta_{i}\end{array}$} & \multirow[t]{2}{*}{ المتغير المستقل } \\
\hline & المعنوية & القيمة & المعنوية & القيمة & & \\
\hline \multirow[t]{2}{*}{$68.2 \%$} & $* 0.008$ & 440.995 & $* 0.002$ & 2.855 & 0.389 & ممارسات إدارة الموارد \\
\hline & & & $* 0.002$ & 21.301 & 0.881 & \\
\hline
\end{tabular}

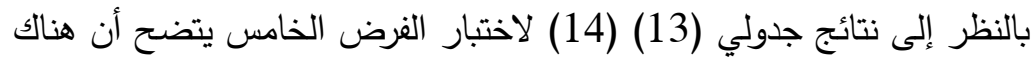

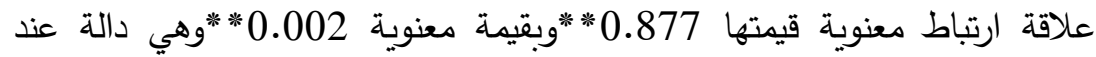
مستوى معنوية أقل من (0.01) الأمر الذي يعنى صحة العلاقة بين ممارسات إدارة

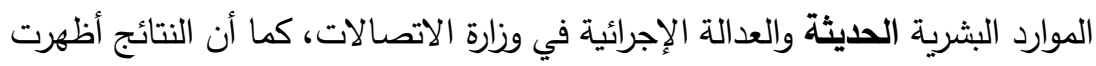


أن ممارسات إدارة الموارد البثرية الحديثة تؤثر على والعدالة الإجرائية في وزارة الاتصالات بنسبة وصلت إلى \% 68.2 مما يعنى أن 68.2\% من العدالة الإجرائية ترجع إلى ممارسات إدارة الموارد البشرية الحليثة. بناءاً على ما سبق في دراسة الفرض الخامس " لا توجد علاقة ذات دلاللة إحصائية

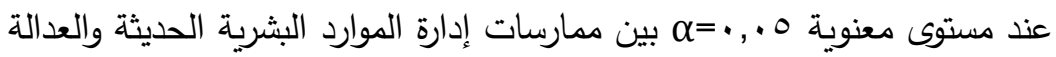

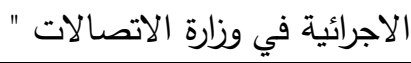

يتضح وجود علاقة بين ممارسات إدارة الموارد البشرية الحديثة والعدالة الاجرائية في وزارة الإتصالات ناتجة و توافق نتائج بعض الدراسات مع عناصر متغيرات الفرضية والعلاقة بينهم مناقشة النتائج

\section{على مستوى الفرض الأول من فروض الاراسة الحالية}

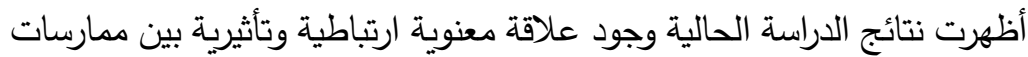

إدارة الموارد البشرية والعدالة التتظيمية في وزارة الاتصالات، هذه النتيجة تعزز توجهات

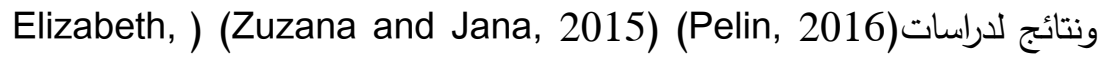
التي أكدت على أن ممارسات إدارة الموارد البشرية تؤثر في بعض (et al., 2017 الجوأنب التنظيمية والإجرائية داخل كيأن المؤسسة، وتعمل على نشر وإثاعة أجواء إداء التهات

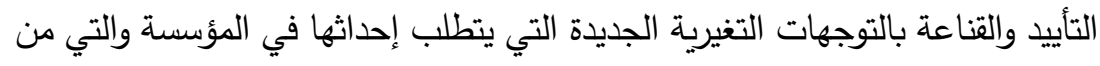
بينها نشر مفاهيم ومظاهر العدالة التتظيمية.

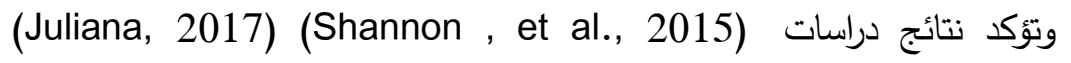
(Russell and Agustin, 2016) التي تحث الموظفين على مبادرات ذاتية تخدم ثقافة المنظمة وتوجهات التغيير المنشود

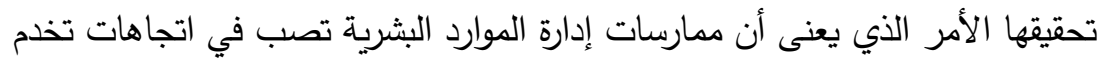


(Silva, التحول إلى مظاهر وثقافة العدالة التظيمية، هذا بجأنب أن نتائج دراسات et al., 2016) (Ebru and Mine, 2016) تقليل الأخطاء التنظيمية وتجنب إهدار الموارد وحسن استغلالها واستدامتها، والتأثير على الارتباط الإيجابي بين الأداء الفردي والمؤسي وهئ إهى أمور مرتبطة بممارسات إدارة الموارد البشرية. وهو ما يؤكد توافق نتيجة الدراسة الحالية مع نتائج الدراسات السابقة المشار اليها فيما يخص ممارسات إدارة الموارد البشرية التي تساهم في تعزيز مفاهيم وتوجهات العدالة التنظيمية بالمنظمات.

\section{على مستوى الفرض الثاني من فروض الدراسة الحالية}

تبين من نتائج الدراسة الحالية على مستوى الفرض الثاني وجود علاقة معنوية من متردية ارتباطية وتأثيرية بين ممارسات إدارة الموارد البشرية التقليدية والعدالة التنظيمية في وزارة الاتصالات، هذه النتيجة تعزز توجهات ونتائج لدراسات (Pelin, 2016) (Zuzana and Jana, 2015) (Elizabeth, et al., 2017) الممارسات التقليدية لإدارة الموارد البشرية تعمل على مسأندة المنظمة في توجهاتها

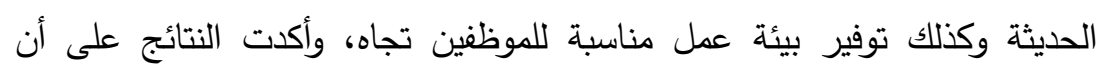
ممارسات إدارة الموارد البشرية التقليدية تصب في مصلحة المؤسسة ومواجهة تغيرات

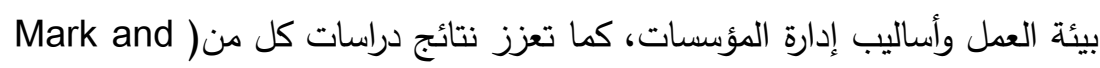

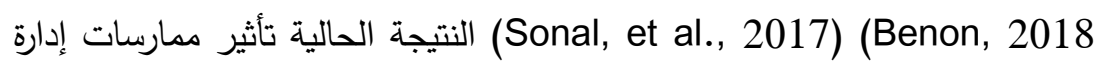
الموارد البشرية على توجهات ودور الأفراد في إحداث التغيير والأنسجام مع متغيرات

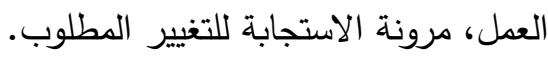


(Tan and Ab Aziz, 2016) (Debjani ,et وتثير نتائج بعض الدراسات (Tayyaba ,et al.,2017) al., 2016) إلى أن هناك أشكال وأنواع من مظاهر العدالة التنظيمية بالإضافة الى ارتباط مفهوم

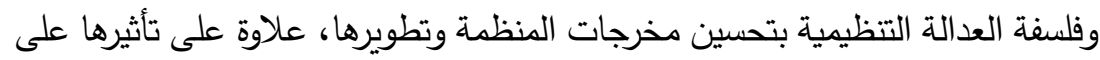
دافعة وتحفيز الأفراد، مما يعزز من الاتجاهات التي تؤيد نتائج اختبار الفرضية الحالية.

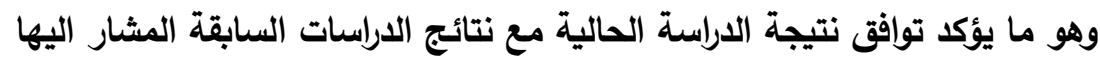

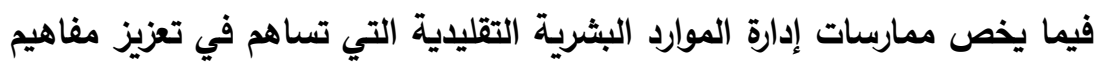
وتوجهات العدالة التنظيمية بالمنظمات.

\section{على مستوى الفرض الثالث من فروض الاراسة الحالية}

اتضح من نتائج الدراسة الحالية على مستوى الفرض الثالث وجود علاقة معنوية ارتباطية وتأثيرية بين ممارسات إدارة الموارد البشرية الحديثة والعدالة التظيمية في (Judie, et.al, وزارة الاتصالات، هذه النتيجة تعزز توجهات ونتائج لدراسات (Akram and Yusuf, 2016) الموارد البشرية لمواكبة العصر الحالي وتحولاته في إدارة العاملين وأداؤهم ومخرجاتهم، بuzana and Jana, ) (Pelin, 2016) بالإضافة الى تعزيز نتائج دراسات (Elizabeth, et al., 2017) عن وجود ممارسات تقليدية وممارسات حديثة لمهام إدارة الموارد البشرية وكلاهما من المهم أن يصب في مصلحة المؤسسة ومواجهة تغيرات بيئة العمل وأساليب إدارة المؤسسات، الأمر الذى يتوافق مع نتائج الفرضية

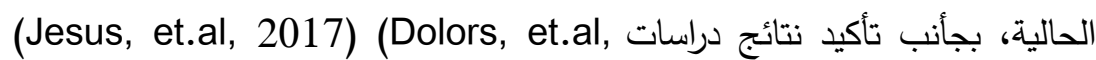
(2018 على التوجهات الحديثة في ممارسات إدارة الموارد البشرية من حيث زيادة 
التركيز على الأصول البشرية ورأس المال الفكرى والبشرى والأصول المنتجة للمعرفة التظيمية والبشرية والابتكار •

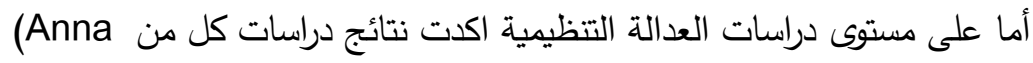

(Shabnam and Parivash, 2012)

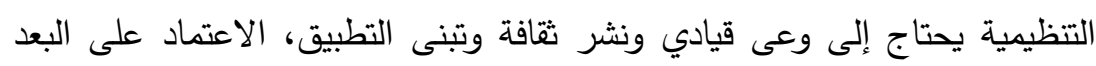

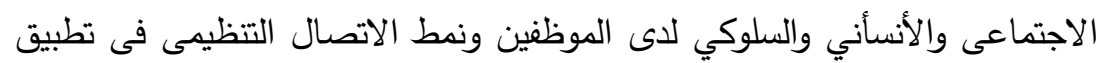
العدالة التظيمية ، بالإضافة الى ما توصلت اليه دراسات (Sow , et al., 2017) (Arzu , et al., 2014) (Meral, et al., 2015) من تقليل أعباء الصراع التنظيمى وزيادة مستويات الرضا الوظيفى، وتغيير نمط الثقافة التظيمية ،وتطور من الأداء البشرى للموظفين وأنتاجيتهم ،وهى كلها أمور تتطلب ممارسات محددة من إدارة الموارد البشرية. وهو ما يؤكد توافق نتيجة الدراسة الحالية مع نتائج الدراسات السابقة المشار اليها فيما يخص ممارسات إدارة الموارد البشرية الحديثة التي تساهم في تعزيز مفاهيم وتوجهات العدالة التظيمية بالمنظمات.

\section{على مستوى الفرض الرابع من فروض الدراسة الحالية}

أسفرت نتائج الدراسة الحالية على مستوى الفرض الرابع وجود علاقة معنوية لردية ارتباطية وتأثيرية بين ممارسات إدارة الموارد البشرية التقليدية والعدالة الإجرائية في

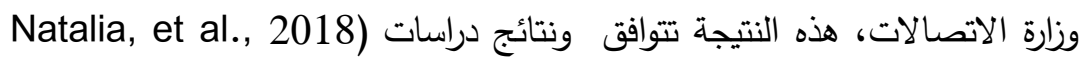

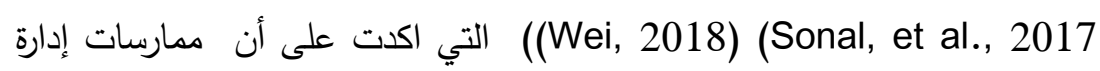

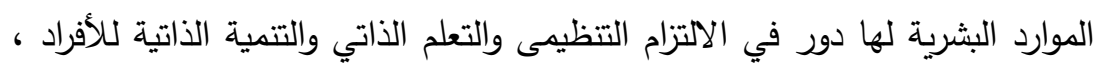

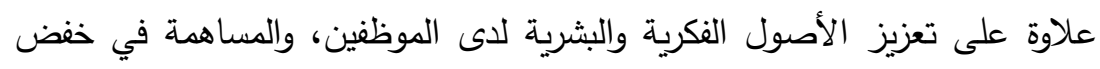


تكاليف تطبيق التوجهات الحديثة في إدارة المنظمة لرفع معدلات أنتاجيتها وعلاج الأخطاء التظظيمية والإجرائية .

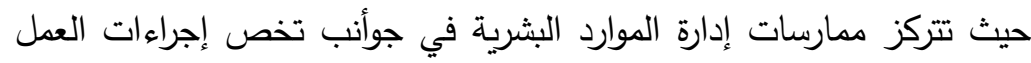

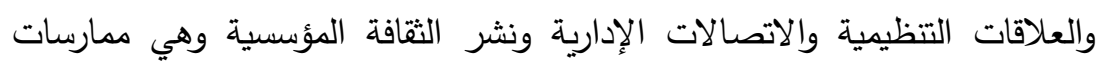

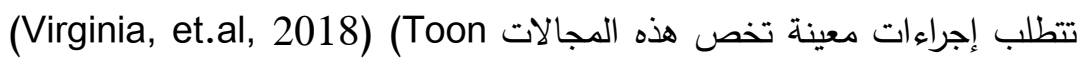
and Thomas, 2018) والمخرجات ودور الأفراد في تفعيل عنصري الكفاءة والفعالية التظيمية والإجراءات المرتبطة بها.

(Tan and Ab Aziz, 2016) (Debjani ,et كما توصلت نتائج دراسات al., 2016) (Tayyaba ,et al.,2017)

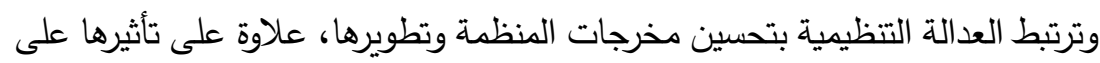

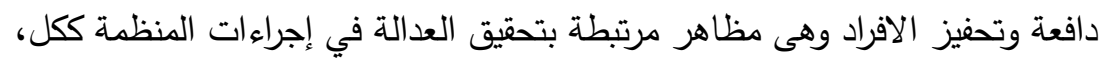

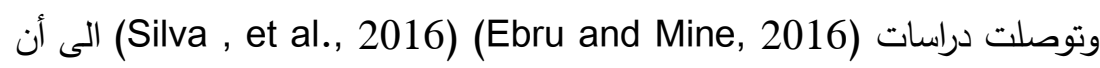
مساهمة العدالة التظظيمية في تقليل الأخطاء التتظيمية وتجنب اهدار الموارد وحسن استغلالها واستدامتها، والتأثير على الارتباط الإيجابي بين الأداء الفردي والمؤسسي الأسي

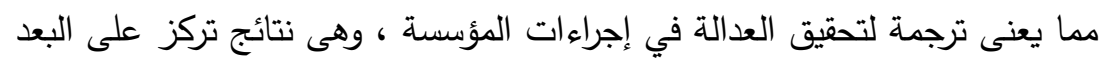
البشرى والوظيفي للعاملين مما يعنى ارتباطها بممارسات إدارة الموارد البشرية.

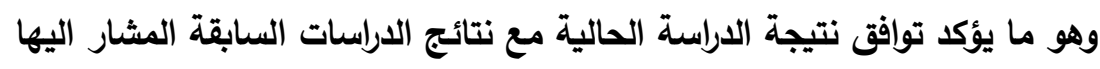

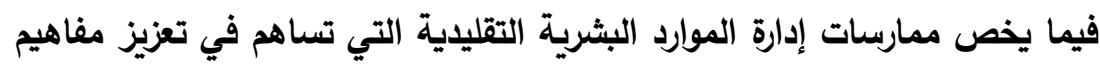
وتوجهات العدالة الاجرائية بالمنظمات. 


\section{على مستوى الفرض الخامس من فروض الدراسة الحالية}

اتضح من دراسة الفرض الخامس لبحث العلاقة بين ممارسات إدارة الموارد

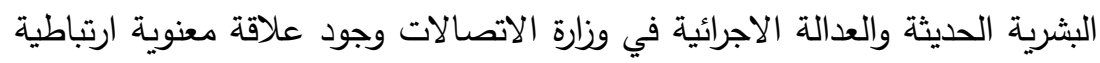

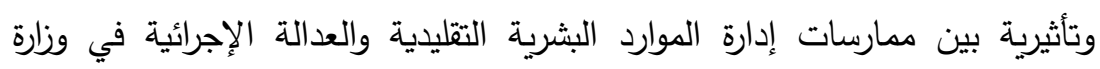

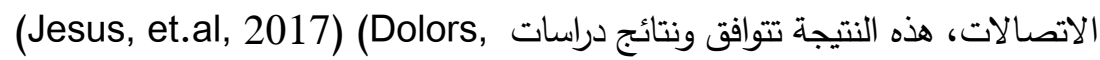
من حيث أنها أظهرت أن هناك تغيير فى توجهات ممارسات إدارة

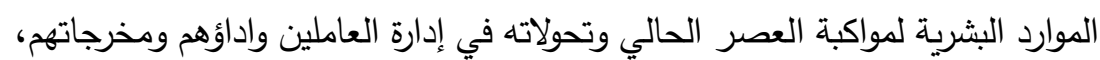
هuzana and Jana, ) (Pelin, 2016) ها وتبين كذلك من نتائج دراسات (2015) (Elizabeth, et al., 2017) وجود ممارسات تقليدية وممارسات حديثة لمهام إدارة الموارد البشرية وكلاهما من المهم أن يصب في مصلحة المؤسسة ومواجهة تغيرات بيئة العمل وأساليب إدارة المؤسسات وهى نتائج تتوافق مع نتائج الفرضية

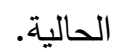
وقد أظهرت دراسات كلا من Notalia, et al., 2018) (Wei, 2018) (Sonal, نتائج متوافقة مع نتائج اختبار الفرض الخامس الحالي من حيث أن (et al., 2017 ممارسات إدارة الموارد البشرية الحديثة تتمثل في الالتزام التظظيمى والتعلم الذاتي والتتمية الذاتية للأفراد ، علاوة على تعزيز الأصول الفكرية والبشرية لدى الموظفين، والمساهمة في خفض تكاليف تطبيق التوجهات الحديثة في إدارة المنظمة لرفع معدلات أنتاجيتها وعلاج الأخطاء التنظيمية والإجرائية. Sow , et al., 2017) وعلى مستوى العدالة الإجرائية جاءت نتائج دراسات والاجهاء (Arzu, et al., 2014) (Meral, et al., 2015 إدارة الموارد البشرية الحديثة بما يؤيد نتائج الفرضية الخامسة الحالية من حيث العدالة

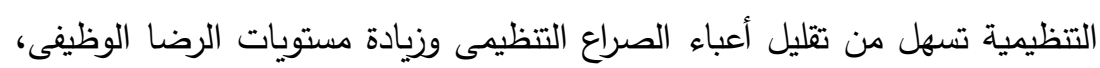


وتغيير نمط الثقافة التتظيمية، وتطور من الأداء البشرى للموظفين وأنتاجيتهم وهى

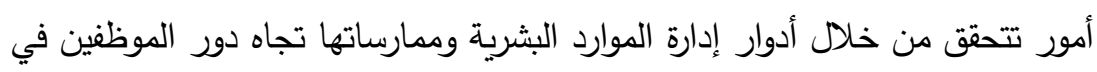

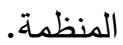

وايدت نتائج دراسات (Shannon, et al., 2015) (لمنات ) (Russell and Agustin, 2016) أنها قد تكون إجرائية او اتصالية او تعامليه او تحفيزية وهى أداة مهمة تساعد في تهيئة بيئة العمل لتتبل التغيير وتطبيق التوجهات الحديثة، وتتبى المبادرات الذاتية من العاملين، وهو ما يتوافق مع نتائج الفرضية الخامسة الحالية. وهو ما يؤكد توافق نتيجة الدراسة الحالية مع نتائج الدراسات السابقة المشار اليها فيما يخص ممارسات إدارة الموارد البثرية الحديثة التي تساهم في تعزيز مفاهيم وتوجهات العدالة الاجرائية بالمنظمات. مقترحات الاراسة

في ضوء النتائج ومناقشتها والاستخلاصات التى توصلت لها الباحثة من خلال قراءتها للنتائج وعلاقتها بالدراسات السابقة، تقترح الباحثة مجموعة من الأمور لتحقيق

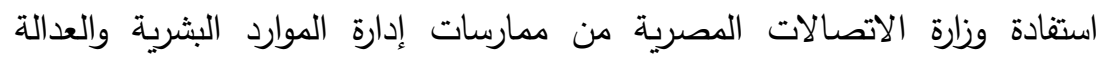

ا. أن يقوم مسئولي إدارات الموارد البشرية في وزارة الاتصالات بإعادة النظر في أنشطة وممارسات تلك الإدارات وتطويرها في ضوه مستجدات العمل في إني إدارة المنظمات الحكومية وتعديل السياسات والإجراءات بشكل مناسب لها،

مع الاخذ في الاعتبار اقتراح التشريعات واللوائح الوزارية المناسبة لذلك.

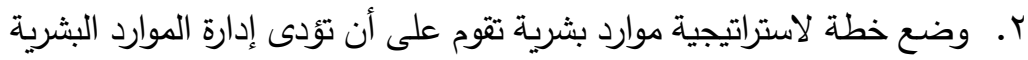

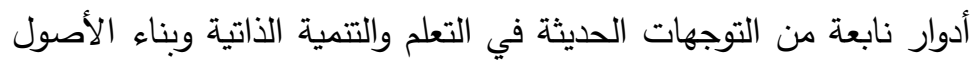


الفكرية والبشرية والمعرفة بحيث يبنى أداء الموظفين على توجهات

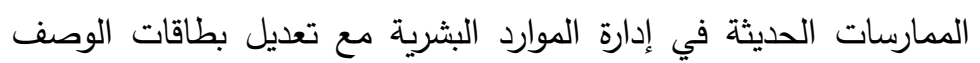
الوظيفى والمهام والاختصاصات بما يتناسب وذلك التوجه.

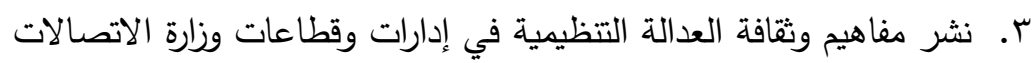

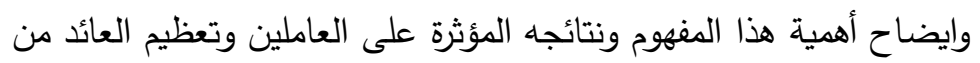
أداء الموظفين والتأثير على كفاءة وفعالية الوزارة.

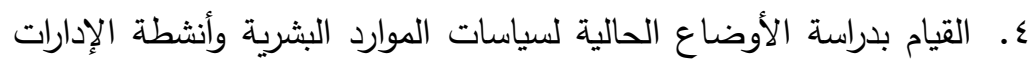
المختصة في ذلك ومدى توافقها مع تحقيق معايير وابعاد العادلة التتظيمية سواء من الناحية الإجرائية او الاتصالية او مفاهيم العادلة التنظيمية بشكل تولئل عام. ๑. مراجعة الوصف الوظيفى للعاملين ومدى تطابقه مع مفاهيم العدالة التظيمية والاجرائية والقيام بتعديل مضمون بطاقات الوصف الوظيفى بما يساهم في تحقيق ذلك. 7. تطوير الإجراءات التظيمية في هيكل وزارة الإتصالات بما يضمن أنسياب

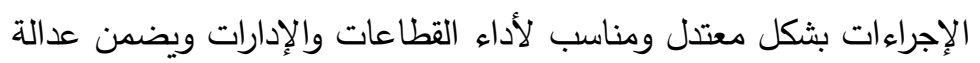

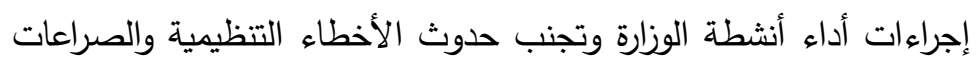
التى تعرقل مسارات العمل بالوزارة. V. اجراء دراسة تحليلية لنقاط القوة والضعف في أداء إدارات الموارد البشرية في الوزارة بما يتتاسب مع توجهات مفاهيم وفكر العدالة التتظيمية والاجرائية حتى تساعد النتائج في معرفة الاليات المناسبة لتطبيق هذه المفاهيم. 


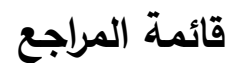

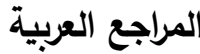

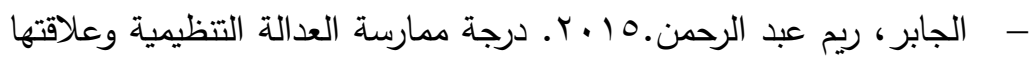
بمستوى سلوك المواطنة التظظيمية بإدارات التربية والتعليم في المملكة العربية

السعودية. مجلة كلية التربية جامعة بنها ، مجلد ب؟، عدد ا، يناير .

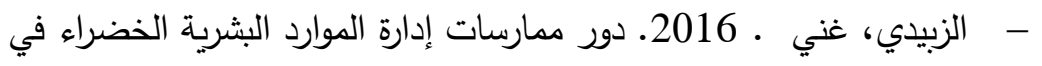

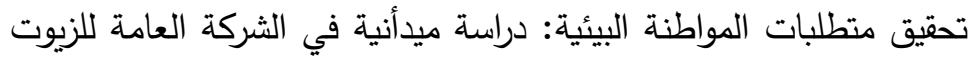

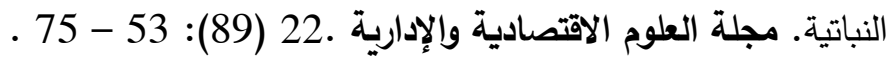

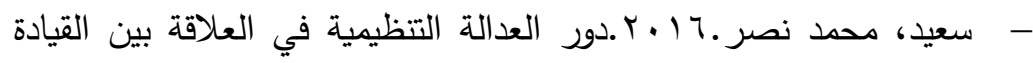
الأخلاقية والالتزام التظيمى :دراسة تطبيقية على العاملين في قطاع الاتصالات المصرية ـ المجلة العلمية للتجارة والتمويل جامعة طنطا ،عدد

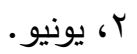
- - الثبيبى، خميس بن صالح بن هويشل.2015. تطوير أداء الموارد البشرية بجامعات سلطنة عمأن فى ضوء معايير الجودة الثاملة. مجلة جامعة الفيوم

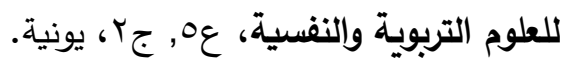

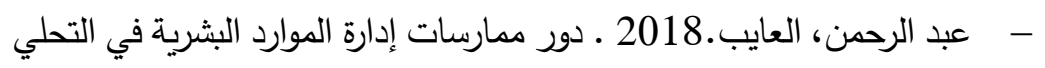
بالمسؤولية الاجتماعية للشركات في المؤسسات الاقتصادية الجزائرية. مجلة

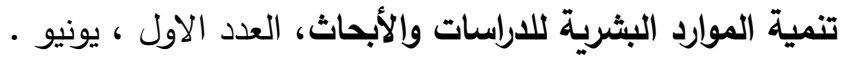

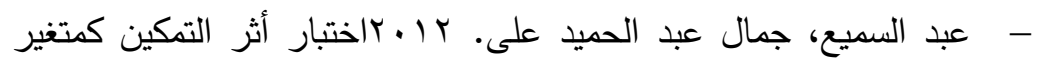
وسيط فى العلاقة بين العدالة التظيمية والولاء التنظيمى : دراسة تطبيقيه

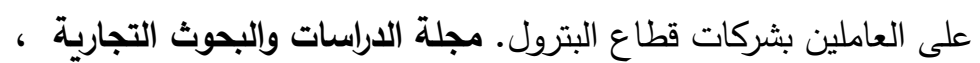
جامعة القاهرة، السنة بس، عدد (، مجلد ب. 
- العزب ، حسين محمد ، و العنزي ، فرج شيلويح · 2013. أثر وظائف إدارة الموارد البشرية على تحقيق التميز المؤسسي: دراسة تطبيقية عل مصلحة الجمارك السعودية. مجلة مؤتة للبحوث والاراسات، سلسلة العلوم الأنسأنية

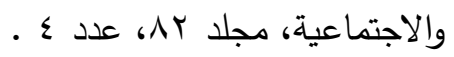

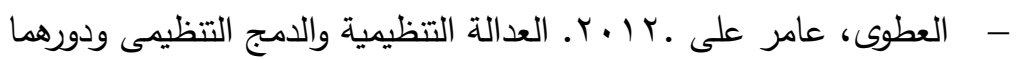

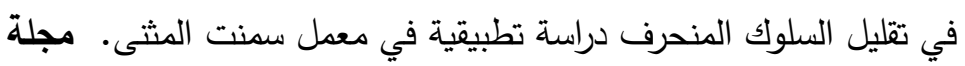
الغزى للعلوم الاقتصادية و الإدارية , السنة السابعة العدد 21.

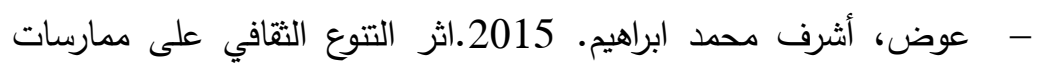
الموارد البشرية: دراسة تطبيقية على المستثفيات التابعة لوزارة الصحة بدولة الامارات العربية المتحدة. المجلة العلمية التجارة والتمويل - جامعة طنطا لطئل . ع - - محمد، بناز عثمأن.2016 .تأثير ممارسات إدارة الموارد البشرية على الأداء

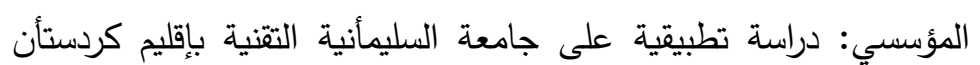

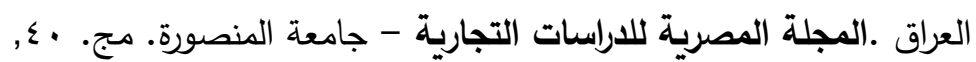
r. - - المغربي، عبد الحميد عبد الفتاح.2014. بناء ثقافة التعلم التنظيمي لتحسين ممارسات إدارة الموارد البشرية: بالتطبيق على الأجهزة الحكومية

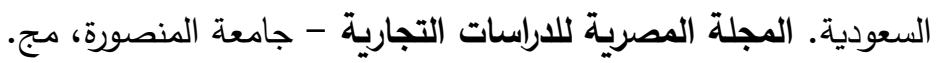
r $\cdot$. 


\section{مراجع اجنبية}

- Afagh, A. N., Noor, M. Y., Habibollah, D., Seyed, Al. R. 2016 . Exploring the Dimensions and Components of Islamic Values Influencing the Productivity of Human Resources from the Perspective of Mashhad Municipality Employees .Social and Behavioral Sciences, V. 230, 12 Sep. : 379-386.

- Akram A.\& Yusuf S.2016. Comparative international human resource management: Future research directions. Human Resource Management Review, V. 26, 4, December: 352-358.

- Anna P., Silvia P., Paola M., Tiziana R.2015. Organizational Justice, Optimism and Commitment to Change. Procedia - Social and Behavioral Sciences, V. 191, 2 June pp.: 1697-1701.

- Arzu S., Meral E., Tanyeri U., Irge S.2014.The Effects of Organizational Justice and Ethical Climate on Perceived Work Related Stress. Social and Behavioral Sciences, V. 150, 15, September, pp.: 1187-1198.

- B Toon Z. \& Thomas V.2018. The employee mobility budget: Aligning sustainable transportation with human resource management?. Transportation Research, Part D: Transport and Environment, V. 61, Part B, June : 383396.

- Benson T.H. L.\& Martin L.2017.The effect of interorganizational justice perceptions on organizational citizenship behaviors in construction projects. International Journal of Project Management, V. 35, 2, Feb. pp.: 95-106.

- Debjani G., Tomoki S., Gurunathan L.2017. Organizational embeddedness as a mediator between 
justice and in-role performance .Journal of Business Research, V. 75, June pp.: 130-137.

- Didem, P. 2016. Analysis of the Relationship Between Human Resources Management Practices and Organizational Commitment from a Strategic Perspective: Findings from the Banking Industry .Social and Behavioral Sciences, V. 207, 20 Oct. : 315-324.

- Dolors C., Esther M., Josep M. 2018. Socially responsible HR practices and their effects on employees' wellbeing: Empirical evidence from Catalonia, Spain. European Research on Management and Business Economics, V. 24, 2, May-August: 82-89.

- Ebru B. B.\& Mine A. F.2016.The Mediating Effect of Job Satisfaction on the Relation between Organizational Justice Perception and Intention to Leave. Social and Behavioral Sciences, V. 235, 24 November pp.: 403-411.

- Elizabeth P. K., William L. G., Daniel P. G., Lori L. T. , Mingwei L.2017. Authentic Leadership and HighPerformance Human Resource Practices: Implications for Work Engagement. Series: Research in Personnel and Human Resources Management, 35, pp.:103 - 153.

- Feodor M., Kolesnikova J., Salyakhov E.2014. Current Tendencies of the Development of Service of Human Resources Management. Social and Behavioral Sciences, V. 150, 15 Sep.:330-335.

- Heidi O., Pia H. L., Pia H.2015. Human resources strength and weakness in protection of intellectual capital. Journal of Intellectual Capital, 16, 4, pp: 742-762.

- Jesus B., Macarena L., Pedro M. 2017. Socially responsible human resource policies and practices: Academic and professional validation. European 


\begin{tabular}{|c|c|c|}
\hline 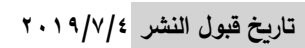 & منال محمد احمد الوكيل & اثر ممارسات إدارة الموارد البشرية تجاه دور الافراد \\
\hline
\end{tabular}

Research on Management and Business Economics, V. 23, 1, January-April: 55-61.

- Journal of Business Research, V. 70, January pp.: 214223.

- Judie M., Angela R., Liz D.2015. Strategic human resource management: Insights from the international hotel industry. International Journal of Hospitality Management, V. 47, May 65-75.

- Juliana, D. L.2017. What happened to civility? Understanding rude behavior through the lens of organizational justice. Business Horizons, V. 60, 5, September-October pp.: 707-714.

- Justin N.\& Scott E. W. 2016 . Sensitivity to the Ferguson Effect: The role of managerial organizational justice. Journal of Criminal Justice, V. 47, December pp.: 1220.

- Mark K. \& Benon C. B .2018. Indigenous Human Resource Management Practices in Africa: Empirical Lessons from Four Sub-regions. Advanced Series in Management, 20, pp.:97 - 118.

- Meral E., Melisa Erdilek K., Bulent A.2015.Investigating the Mediating Effect of Ethical Climate on Organizational Justice and Burnout: A Study on Financial Sector. Social and Behavioral Sciences, V. 207, 20 October, pp.: 587597.

- Mohd Y. Y., Nur Z. O., Charbel J. C. J.2017. Deciphering the implementation of green human resource management in an emerging economy. Journal of Management Development, 36, 10, pp.:1230-1246.

- Natalia G. C., Fernando M. A., Gonzalo S. G.2018. Determinants of building consistent human resources management systems: A focus on internal 
communication. International Journal of Manpower, 39, 3, pp.:354-377.

- Parivash J., Shabnam B. 2012.The Relationship Between Organizational Justice and Organizational Citizenship Behavior. Procedia - Social and Behavioral Sciences, V. 47, pp.: 1815-1820.

- Pelin ,V. 2016. Strategic Approach to Human Resources Management During Crisis .Social and Behavioral Sciences, V.235, 24 Nov. : 463-472.

- Russell C. \& Agustin M.2015. Organizational Justice. International Encyclopedia of the Social \& Behavioral Sciences , Second Edition, pp.: 379-384.

- Shabnam B.\& Parivash J.2012.The Relationship Between Organizational Justice and Organizational Trust Shabnam .Social and Behavioral Sciences, V. 47 pp.: 1622-1626.

- Shannon K., Jeremy S. J., Brian A. T. 2015 .Organizational justice and conflict: Do perceptions of fairness influence disagreement?. Sport Management Review, Volume 18, Issue 3, August pp.: 384-395.

- Silva K., Guy A., Rob H.2016.An empirical study of 360degree feedback, organizational justice, and firm sustainability. Journal of Business Research, V.69, 5, May pp.: 1862-1867.

- Sonal A. , Ginni C., Rupali S.2017. Innovations in human resource practices: measurement development and validation. International Journal of Innovation Science, 9, 4, pp.: 396-416.

- Sow H., Joanne C., Ho Y., Isabella L.2017.Understanding the link between communication satisfaction, perceived justice and organizational citizenship behavior 
- Tan F. Y. \& Ab Aziz Y.2016.Organizational Justice: A Conceptual Discussion . Social and Behavioral Sciences, V. 219, 31 May pp.: 798-803.

- Tayyaba, A., Shen L., Muhammad, J.H., Syed, T. H., Lilian, C. M. P.2017. The effect of organizational justice on knowledge sharing: Empirical evidence from the Chinese telecommunications sector. Journal of Innovation \& Knowledge, V. 2, 3September-December pp.: 134-145.

- Virginia B., Esther P., Juan B.2018. Human resource practices and organizational human capital in the family firm: The effect of generational stage. Journal of Business Research, V. 84, March: 337-348.

- Wei L .2018. High-involvement human resource practices, employee learning and employability. Career Development International, 23, 3, pp.:312-326.

- Zuzana, J.\& Jana, B. 2015. Age Management as Contemporary Challenge to Human Resources Management in Slovak Companies . Economics and Finance, V. 34, : 202-209. 
Abstract
The impact of human resources management practices on the role of individuals in achieving organizational justice in public institutions - An applied study on the Ministry of Communications

The aim of this study is to examine the relationship between human resources management practices and the role of individuals in achieving organizational justice in the Ministry of Communications. It also aims to examine the relationship between traditional practices and modern human resources management practices in terms of organizational justice and their contribution to the Ministry of Communications.

The results of the study were based on the importance of the relationship between traditional and modern human resources management practices as independent variables and organizational justice as a variable. The value of the regression coefficient was significant at $0.05=\alpha$, indicating the validity of the effect relationship.

The study recommended that human resources management should take into account the activities that contribute to the promotion of organizational justice between the two employee in the Ministry of Communications as it contributes to enhancing satisfaction, increasing employee productivity, achieving the Ministry's effectiveness and achieving the goals.

Key Words: Human Resource Management - Human Resources - Traditional Human Resource Management Practices - Modern Human Resource Management Practices - Organizational Justice - Ministry of Communications. 


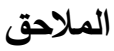 \\ الاستبأنة}

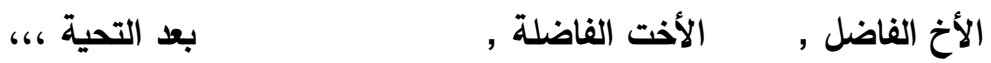

يطيب لي أن أشكركم مقدما على استجابتكم الكريمة نحو أنجاز هذه الدراسة مقدرين الأني

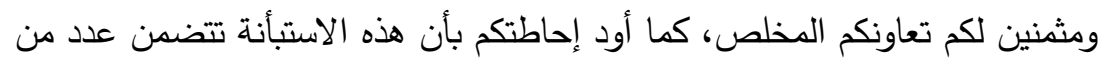

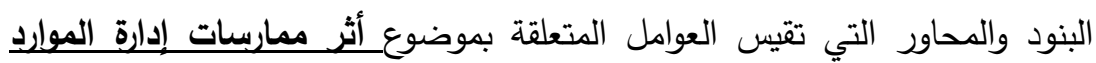

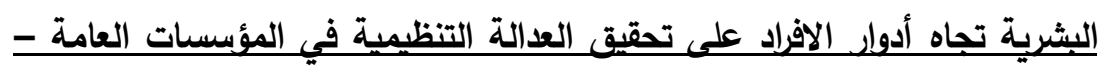
دراسة تطبيقية على وزلارة الاتصالات، كما نؤكد لكم على أن كل ما تلدئ الون به من آراء

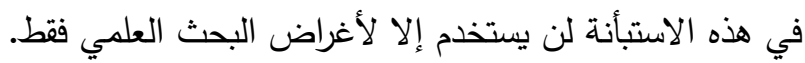

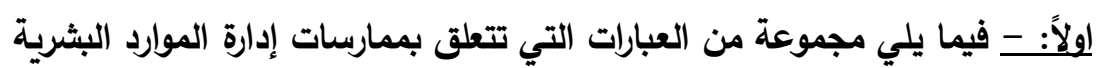

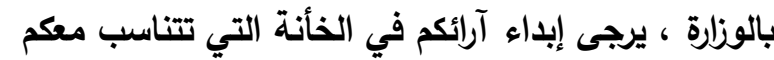

\begin{tabular}{|c|c|c|c|c|c|c|}
\hline موافاً & موافق & محايد & $\begin{array}{l}\text { غوافير } \\
\text { غو (r) }\end{array}$ & تماما (1) & 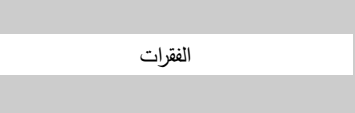 & e \\
\hline & & & & & تبالوزارة للتحفيز المادى لـى ادارة الموارد البشرية & 1 \\
\hline & & & & & تالتحفيز الدعنوي بالوزارة البرارية على تطبيق اسلوب & r \\
\hline & & & & & يتسم أسلوب التحفيز بالوزارة بالثفافية والعدالة & $r$ \\
\hline & & & & & تلتحفيز وفق المستجدات البرات بارية بالوزارة من اسلوب & $\varepsilon$ \\
\hline & & & & & تشتجع ادارة الموارد البشرية بالوزارة العاملين & . \\
\hline & & & & & تلمتح ادارة الموارد البشرية مكافات عينية & 1 \\
\hline & & & & & تهتمت ادارة الموارد البشرية بتحفيز الموظفين & $\mathrm{v}$ \\
\hline & & & & & كتمتم ربط الحوافز بالأداء البشرى تثجيعا & $\wedge$ \\
\hline
\end{tabular}




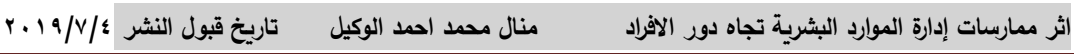

\begin{tabular}{|c|c|c|c|c|c|c|}
\hline تمامأ & 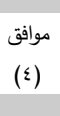 & محايد & $\begin{array}{l}\text { غوافير } \\
\text { (广) }\end{array}$ & ت تماما (1) & الفقرات & م \\
\hline & & & & & تمتح ادارة الموارد البشرية بالوزارة فرصة تدريبية & 9 \\
\hline & & & & & تحرص الادارة العليا بالوزارة على تكريم & 1. \\
\hline & & & & & تلعقل ادارة الموارد البشرية على تتويع اساليب & 11 \\
\hline & & & & & بالوزارة طرق متوعة للتحفيز المادى للعاملين & Ir \\
\hline & & & & & تطلى تطوير الاداء البشرى البوارية نظام تحفيز مشجع & ir \\
\hline & & & & & 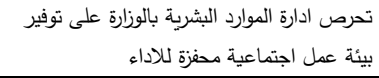 & $1 \varepsilon$ \\
\hline & & & & & 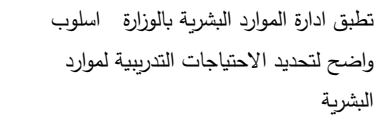 & 10 \\
\hline & & & & & تلتبق ادارة الدوارد البشرية بالوزارة البرامج & 17 \\
\hline & & & & & تحتيث الموارد البشرية وقدرتهم لاستيعاب كل ما هو البشرية بالوزار بتطوير مهارات & iv \\
\hline & & & & & 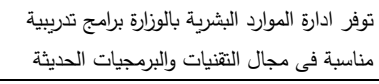 & 11 \\
\hline & & & & & 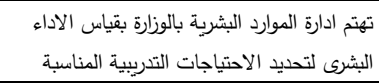 & 19 \\
\hline & & & & & المطائف للوقوف الموارد البشرية بالوزارة على تحليل الاحتياجات التنريبية & $r$. \\
\hline & & & & & 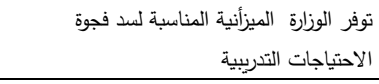 & rI \\
\hline & & & & & 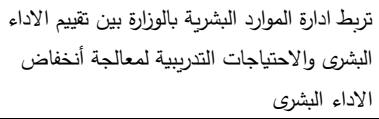 & rr \\
\hline
\end{tabular}




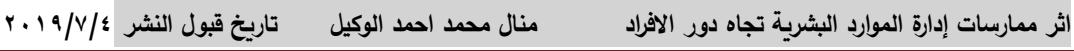

\begin{tabular}{|c|c|c|c|c|c|c|}
\hline تمامأ موأق & موافق & محايد & $\begin{array}{l}\text { غوافير } \\
\text { غو (r) }\end{array}$ & تماما (1) & الفقرات & ? \\
\hline & & & & & 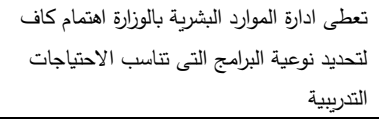 & rr \\
\hline & & & & & تهتم ادارة الموارد البشرية بصقل مهارات & $r \leqslant$ \\
\hline & & & & & 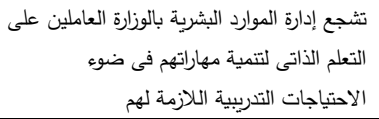 & ro \\
\hline & & & & & توفر ادارة الموارد البشرية محفزات لاستقطاب & rT \\
\hline & & & & & تلاجتيار والتعيين وفقص معايير واضحة ادارة الموارد البشرية & TY \\
\hline & & & & & لادى ادارة الموارد البشرية خطة لاستكثاف & ru \\
\hline & & & & & 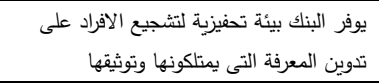 & rq \\
\hline & & & & & ابتكارى متيمز معرفة بالافراد الذين يمتلكون اداء & $r$. \\
\hline & & & & & تسهم في حل مشكلات البنك موارد بشرية لايهم معرفة واضحة & ri \\
\hline & & & & & يتم تداول المعرفة بين العاملين في المستويات & rr \\
\hline
\end{tabular}


ثأنياً:- فيما يلي مجموعة من العبارات التي تتعلق بالعدالة التنظيمية وعدالة

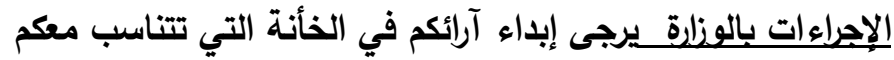

\begin{tabular}{|c|c|c|c|c|c|c|}
\hline موافق & موافق & محايد & غوافير & غير موافق & الفقرات & e \\
\hline & & & & & توفر الوزارة للعاملين إجراءات عمل ميسرة & 1 \\
\hline & & & & & يتم اتحاذ القرارات في ضوء مشاركة & r \\
\hline & & & & & 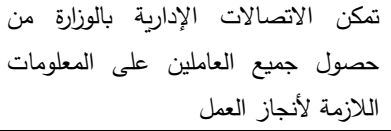 & $r$ \\
\hline & & & & & الازدواجية وتعقد إجراءاء العمل بالوزارة بتلافي & $\varepsilon$ \\
\hline & & & & & 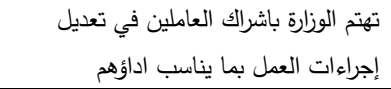 & 0 \\
\hline & & & & & هناك تناسب للهيكل التظظيمى مع إجراءات & 1 \\
\hline & & & & & يخضع جميع العاملين للإجراءات واللوائح & V \\
\hline & & & & & تاعباء الوزاءرة العرات عادلة تتعلق بتوزيع & $\wedge$ \\
\hline & & & & & 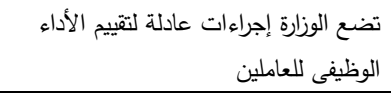 & 9 \\
\hline & & & & & بالوزارة بالتعامل الودى مع كافة الموظفين & 1. \\
\hline & & & & & الوظيفى الموظفين على حل مشكلات اداؤهم & 11 \\
\hline & & & & & 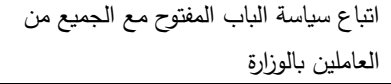 & IT \\
\hline & & & & & تستى اهتمامي حقوق الموظف وتوضحيها لهم & $1 T$ \\
\hline
\end{tabular}




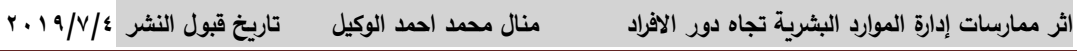

\begin{tabular}{|c|c|c|c|c|c|c|}
\hline موافق & موافق & محايد & موافق & غماما (1) غوافق & 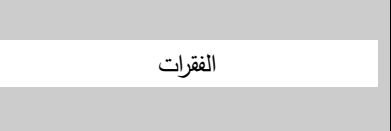 & 5 \\
\hline & & & & & بالوزارة وقت للاستماع لثكوى الموظفين & $1 \varepsilon$ \\
\hline & & & & & 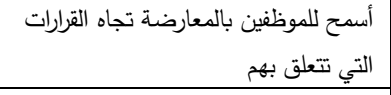 & 10 \\
\hline & & & & & نتائج اداؤهم ناقشا صريح مع الموظفين في مناقشة & 17 \\
\hline & & & & & مهمة بالنسبة لى الأنسأنية تجاه العاملين بالوزارة & iv \\
\hline & & & & & لجهودهم الترقيات لمن يستحقها تقديرا & 11 \\
\hline & & & & & اتبع مبدا المساواة في التعامل مع الموظفين & 19 \\
\hline & & & & & لمستجدات العزارة بتعديل نظام الحوافز وفقا & r. \\
\hline & & & & & تظظر الوزارة بعين الاعتبار للتظلمات من & r) \\
\hline & & & & & تلمتوم قيادات الوزارة بمنح شهادات تقدير & rr \\
\hline & & & & & العاملين الوزارة قيم مالية عادلة لجهود & r \\
\hline & & & & & تتيح الوزارة الفرصة للعاملين لأبداء الرأي & $r \varepsilon$ \\
\hline
\end{tabular}




\begin{tabular}{|c|c|c|}
\hline 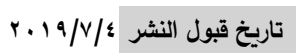 & منال محمد احمد الوكيل & اثر ممارسات إدارة الموارد البشرية تجاه دور الافراد \\
\hline الموارد البشرية العدالة & عن ممارسات إدا & ما هو أنطباعكم بشكل \\
\hline
\end{tabular}

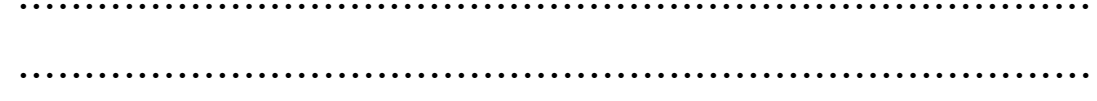

سادساً: ما مقترحاتكم للتغلب على تلك المعوقات؟

مع خالص التقدير والاحترام والثكر

الباحثة

المجلة العلمية للاقتصاد والتجارة 